\title{
BMJ Open Quality indicators for responsible use of medicines: a systematic review
}

To cite: Fujita K, Moles RJ, Chen TF. Quality indicators for responsible use of medicines: a systematic review. BMJ Open 2018;8:e020437. doi:10.1136/ bmjopen-2017-020437

- Prepublication history and additional material for this paper are available online. To view these files, please visit the journal online (http://dx.doi. org/10.1136/bmjopen-2017020437).

Received 6 November 2017 Revised 26 April 2018 Accepted 13 June 2018

Check for updates

(C) Author(s) (or their employer(s)) 2018. Re-use permitted under CC BY-NC. No commercial re-use. See rights and permissions. Published by BMJ.

School of Pharmacy, Faculty of Medicine and Health, The University of Sydney, Sydney, New South Wales, Australia

Correspondence to

Kenji Fujita;

kfuj2522@uni.sydney.edu.au

\begin{abstract}
Objective All healthcare systems require valid ways to evaluate service delivery. The objective of this study was to identify existing content validated quality indicators (Qls) for responsible use of medicines (RUM) and classify them using multiple frameworks to identify gaps in current quality measurements.
\end{abstract}

Design Systematic review without meta-analysis.

Setting All care settings.

Search strategy CINAHL, Embase, Global Health, International Pharmaceutical Abstract, MEDLINE, PubMed and Web of Science databases were searched up to April 2018. An internet search was also conducted. Articles were included if they described medication-related Qls developed using consensus methods. Government agency websites listing QIs for RUM were also included. Analysis Several multidimensional frameworks were selected to assess the scope of QI coverage. These included Donabedian's framework (structure, process and outcome), the Anatomical Therapeutic Chemical (ATC) classification system and a validated classification for causes of drug-related problems (c-DRPs; drug selection, drug form, dose selection, treatment duration, drug use process, logistics, monitoring, adverse drug reactions and others).

Results 2431 content validated Qls were identified from 131 articles and 5 websites. Using Donabedian's framework, the majority of Qls were process indicators. Based on the ATC code, the largest number of Qls pertained to medicines for nervous system (ATC code: $\mathrm{N})$, followed by anti-infectives for systemic use (J) and cardiovascular system (C). The most common c-DRPs pertained to 'drug selection', followed by 'monitoring' and 'drug use process'.

Conclusions This study was the first systematic review classifying Qls for RUM using multiple frameworks. The list of the identified Qls can be used as a database for evaluating the achievement of RUM. Although many QIs were identified, this approach allowed for the identification of gaps in quality measurement of RUM. In order to more effectively evaluate the extent to which RUM has been achieved, further development of Qls may be required.

\section{INTRODUCTION}

Responsible use of medicines (RUM) is an essential element in achieving quality of care for patients and the community. According to the WHO, RUM implies that the activities, capabilities and existing resources of health system stakeholders are aligned to
Strengths and limitations of this study

- A comprehensive literature search was undertaken across seven databases and government agency websites without restriction of disease categories and care settings.

- The classification of quality indicators (QIs) was based on multiple frameworks (eg, Donabedian's framework, the Anatomical Therapeutic Chemical classification system and a validated classification for causes of drug-related problems) for maximum understanding and profiling of the included Qls.

- Content validated Qls that were developed using consensus methods were only included, and therefore valid QIs might have been excluded during the screening process.

- Although $5 \%$ of this review processes were verified by multiple authors to check for accuracy, most of the classification was undertaken by one author.

ensure patients receive the right medicines at the right time, use them appropriately and benefit from them. ${ }^{1}$ RUM, however, is not easily achievable, and if medicines are used inappropriately, negative consequences for both patients and/or the society may occur. It is reported that worldwide more than $50 \%$ of all medicines are prescribed, dispensed or sold inappropriately, while $50 \%$ of patients fail to take them correctly. ${ }^{2}$ In addition, it has been reported that one-third of preventable drug-related admissions are associated with medication non-adherence, $31 \%$ are related to prescribing problems and $22 \%$ are related to monitoring problems. ${ }^{3}$ The frequency of these medication errors varies depending on the specific medicine. For example, previous systematic reviews have found that preventable drug-related admissions to hospital accounted for $3.7 \%$ of all admissions, of which four groups of drugs, antiplatelets, diuretics, non-steroidal anti-inflammatory and anticoagulants accounted for more than $50 \%$ of the drug groups associated with those preventable drug-related hospitalisations. ${ }^{3}$ From the economic perspective, globally, the cost associated with medication errors has been estimated at US $\$ 42$ billion annually or almost 
$1 \%$ of total global health expenditure. ${ }^{4}$ Given the health concerns and the economic burden associated with medication errors, the achievement of RUM underpinned by an evidence-based approach has become increasingly important worldwide.

One critical element for any healthcare system or organisation is how to measure and evaluate RUM. A widely used method to do this is the use of quality indicators (QIs). ${ }^{56}$ QIs are explicitly defined and measurable items referring to the structures, processes or outcomes of care are usually described with a denominator and a numerator. ${ }^{7}$ The denominator is the total number of cases in the intended population, and the numerator is the number of cases that fulfil a predetermined criterion, and the calculated QI score indicates the quality of care. ${ }^{8}$ QIs can be used to monitor the quality of care provided by healthcare professionals in a single institution, to promote quality improvement activities, to make comparisons over time between institutions or to support consumers to choose healthcare providers. ${ }^{5}$ For QIs to be useful, they must be developed with scientific rigour, and all quality dimensions of care must be measured to capture a comprehensive landscape of healthcare quality. ${ }^{5}$

To achieve RUM using QIs, it is first necessary to identify existing QIs for RUM, independent of disease categories and care settings. Additionally, in the light of the concept of RUM, multifaceted assessment is required to gain full understanding of the breadth of coverage by QIs. To our knowledge, however, previously conducted systematic reviews have been restricted to setting (eg, hospital) ${ }^{9}$ disease state (eg, HIV/AIDS),$^{10}$ specific to a healthcare group (eg, nursing sensitive QIs) or indicator name (eg, clinical indicators) ${ }^{11}$ and have only been classified based on Donabedian's framework or implicit frameworks such as quality dimensions defined by the Institute of Medicine. ${ }^{12}$ Hence, the main purpose of this systematic review was to identify existing content validated QIs for RUM independent of disease category and care settings, and then classify them using multiple frameworks in order to identify gaps in current quality measurements.

\section{METHODS}

\section{Data sources}

This systematic review was performed in accordance with the Preferred Reporting Items for Systematic Reviews and Meta-Analyses statement (see online supplementary table S1). ${ }^{13}$ Two approaches were used to identify relevant QIs.

First, CINAHL, Embase, Global Health, International Pharmaceutical Abstract, MEDLINE, PubMed and Web of Science databases were searched to identify relevant articles published up to 5 April 2018. No restriction on year of study was applied. Search strategies comprised keywords and, when available, controlled vocabulary such as Medical Subject Headings/EMTREE based on three main terms: 'quality indicators', 'development' and 'consensus'. Since 'quality indicators' are referred to by wide variety of terms such as clinical indicators, or performance measures, the finalised search strategies were developed using an iterative development process during which citations identified by various search terms were screened for relevance. We chose 'consensus' as a main term because QIs are recommended to be developed using expert panels based on rigorous evidence in order to ensure high face validity and content validity. ${ }^{14}$ Exact search dates for each database with the search strategies are included in online supplementary table S2.

Second, using Google, an internet search was also conducted (search terms: quality indicators, clinical indicators, performance indicator or performance measures) to capture additional QIs listed in the websites of relevant organisations responsible for quality improvement. Potentially relevant organisation's websites, found in the process of literature review, ${ }^{9}{ }^{12} 15-17$ were also searched (see online supplementary table S3).

\section{STUDY SELECTION \\ Inclusion criteria}

Articles were included if they fulfilled the following criteria: (A) the article was peer reviewed and published in English, (B) numerators and denominators were defined for the QIs, or they could be directly deduced from the descriptions of the QIs, $(\mathrm{C})$ the publication contained at least one medication-related QI, (D) the development of QIs was one of the objectives and (E) QIs were developed using consensus methods in order to confirm content validity. Furthermore, relevant organisations' QIs found from websites were included if the organisation was a government agency for ensuring quality in healthcare, and at least one QI for RUM was reported with a clear description, as detailed above (B).

Given the concept of QIs and RUM mentioned above, we regarded a measurement tool as a QI for RUM when the definition of the QI referred to a medication. In addition, if publications concerned the same project/QIs set, the descriptions of the QIs in the most recent publication were used for data extraction.

\section{Exclusion criteria}

Articles were excluded if the consensus results for QI development were unclear, if QI lists were obtainable only by purchase or if QIs were for monitoring the effectiveness of national policies.

This study selection process was performed using a purposed designed screening proforma (see online supplementary table S4). The retrieved articles were transferred into Endnote to remove duplicates, then initial screening of journal names, titles and abstracts was conducted to remove irrelevant articles.

\section{DATA EXTRACTION}

One researcher $(\mathrm{KF})$ extracted the following data from the full text of included articles or websites: publication year, country or other targeted location in which QIs were 
intended to be used, name of measurement tools, total number of QIs, the number of relevant QIs for RUM, scope of the QIs and definition of QIs (numerator and denominator, if available). A data extraction proforma was designed, pilot-tested on five included studies, then refined accordingly.

\section{ANALYSIS}

Descriptive statistics were computed for the results of the present review based on counts and proportions where relevant. Since the components of RUM are multidimensional, multiple frameworks were used to understand the breadth of coverage by QIs. That is, we used four types of classification: (1) problem type; (2) Donabedian's framework; (3) the Anatomical Therapeutic Chemical (ATC) classification system; and (4) causes of drug-related problems (c-DRPs) classification system.

\section{Problem type}

The first step of a structured QI development process is to identify the problem for which measurement is needed. ${ }^{18}$ Classifying QIs according to problem type can highlight prioritised problems for QI development. Therefore, QI sets described in each source were classified into the following six problem types proposed by Evans $e t \mathrm{al}^{18}$ :

1. Disease based: problems relevant to diseases, illnesses, conditions, injuries or procedures for which the quality of care needs to be measured.

2. Patient based: problems related to patient groups, such as vulnerable elders and paediatric patients.

3. Treatment modality based: problems relevant to service providing areas, such as intensive care units or palliative care settings.

4. Organisation based: problems relevant to organisational issues, such as whether organisations have effective structures in place at an organisational level to support quality and safety.

5. Generic problems: problems relevant to issues that are multidisciplinary in nature and relevant to any form of healthcare delivery in multiple physical settings, such as falls prevention, or pain management.

6. Profession based: problems unique to the different healthcare professions and include availability and competence of healthcare personnel.

If a QI set related to more than one problem type, they were classified accordingly (eg, an article about QIs for nursing practice in the operating room fell into treatment modality-based and profession-based problem).

\section{Donabedian's framework}

QIs were classified according to the widely used Donabedian's framework of structure (referred to the factors that designate the conditions under which care is provided, such as material or human resources), process (referred to the actions of healthcare professionals, such as prescribing or monitoring) or outcome (referred to the changes in individuals that can be attributed to care provided), irrespective of the category defined in the original source. ${ }^{19}$ Online supplementary table S5 lists examples of QIs classified into these three categories.

\section{The ATC classification system}

QIs were first classified into medicine class specific indicators or general medication indicators, depending on whether the definition of the QI described a specific class of medicines. For example, a QI 'numerator: patients with acute myocardial infarction (AMI) received aspirin within 3 hours of hospital arrival/denominator: AMI patients without aspirin contraindications, ${ }^{20}$ was classified as a medicine class specific indicator, while a QI 'numerator: number of patients aged 65 years and older whose current medications are documented and reconciled at admission/denominator: number of patients aged 65 years and older in sample ${ }^{, 21}$ was classified as a general medication indicator. After this process, medicine class specific indicators were classified using the first and second levels of the ATC code. ${ }^{22}$ A single QI was sometimes allocated into more than one ATC code. For example, a QI, 'percentage of patients using opioids with concomitant laxatives', ${ }^{23}$ represented A06 (drugs for constipation) and N02 (analgesics).

\section{c-DRPs classification system}

Since minimising the factors that contribute to drug-related problems (ie, causes of DRPs) is closely linked to achieving RUM, the extracted QIs were classified using a comprehensive taxonomy of the causes of DRPs. ${ }^{24}$ This taxonomy divides c-DRPs into the following nine categories.

1. Drug selection, for example, whether appropriate drugs are selected by healthcare professionals.

2. Drug form, for example, whether appropriate drug forms are selected by healthcare professionals.

3. Dose selection, for example, whether appropriate drug dosages are selected by healthcare professionals.

4. Treatment duration, for example, whether drugs are being prescribed or dispensed for an appropriate duration by healthcare professionals.

5. Drug use process, for example, whether drugs are taken properly by patients.

6. Logistics, for example, whether necessary drugs are properly delivered to the patients.

7. Monitoring, for example, monitoring for the effect/ adverse effects of drugs.

8. Adverse drug reactions, for example, the occurrence of adverse drug reactions.

9. Other.

Note that a single QI was sometimes allocated into more than one c-DRP category. Online supplementary table S6 illustrates how QIs were classified using the c-DRP taxonomy.

All processes were conducted independently by one author $(\mathrm{KF})$, and $5 \%$ of these processes were verified by TFC and RJM. Any issues that arose during the process were resolved by discussion between the research team 


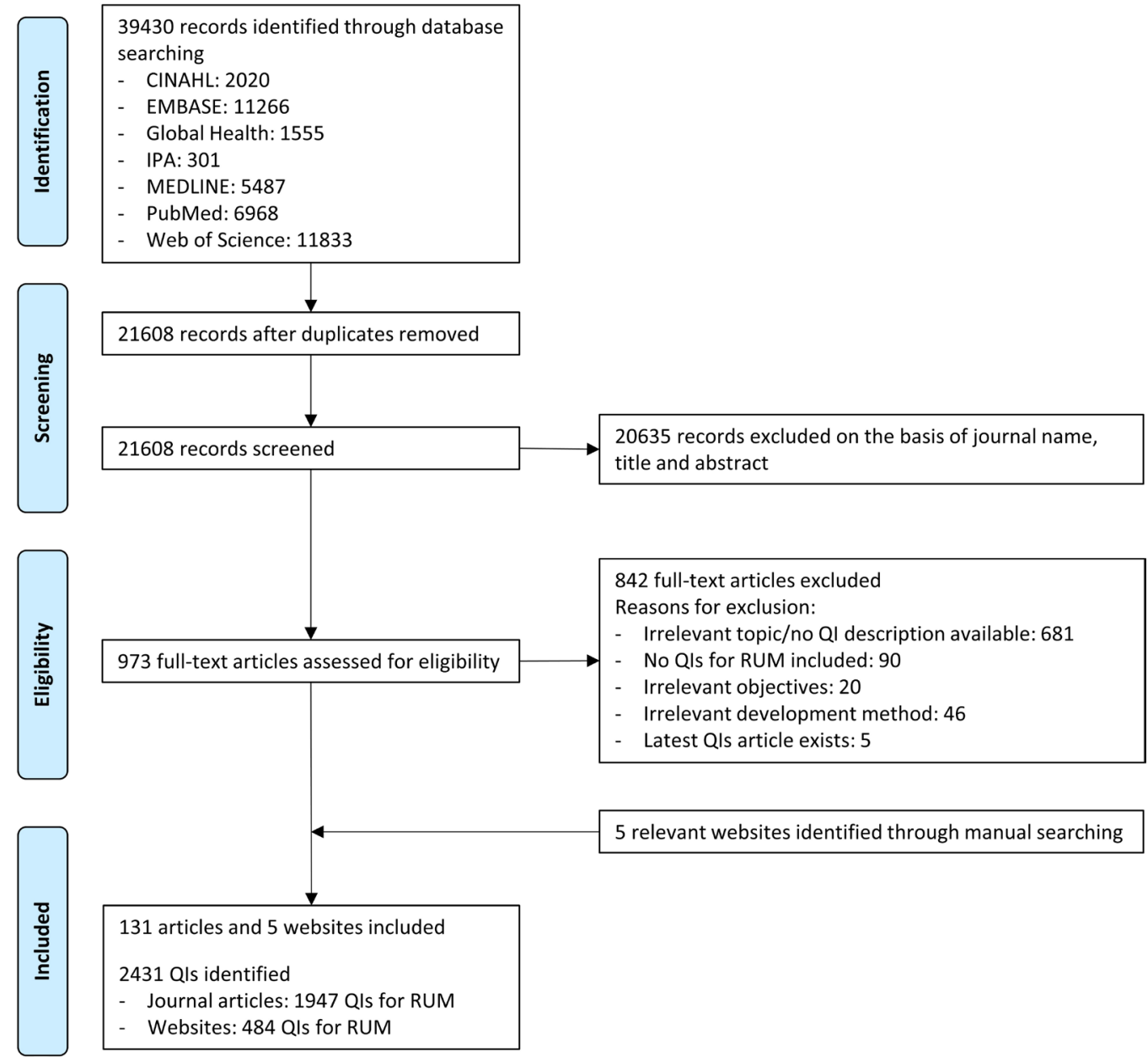

Figure 1 Study flow diagram. QI, quality indicator; RUM, responsible use of medicines.

(KF, RJM and TFC). Meta-analysis was not applicable due to heterogeneity in interventions, methods and reported outcomes. We believed that it was not necessary to assess the quality of the content validated QIs included in our studies such as their feasibility, and reliability because problems affecting QIs (eg, feasibility of data collection, reliability of calculating QI scores and opportunities for gaming) vary depending on the healthcare infrastructure and healthcare remuneration system in each country.

\section{PATIENT AND PUBLIC INVOLVEMENT}

As this was a literature review, there was no patient and public involvement in this study.

\section{RESULTS}

\section{Study selection}

Initially, a total of 39430 articles were obtained. The sample included 17822 duplicate records, which were removed. After the initial screening, 973 full texts were assessed for eligibility with 842 excluded based on the inclusion and exclusion criteria. Eventually 131 articles met all inclusion criteria and were included in our review. Additionally, through the internet search, five relevant websites were identified and included in our review (figure 1).

\section{Study characteristics}

Of the 131 articles, 78 articles $(60 \%)$ developed QIs for use in three countries: USA $(\mathrm{n}=36),{ }^{25-60}$ Canada $(\mathrm{n}=26)^{61-86}$ and Netherlands $(\mathrm{n}=16){ }^{23}{ }^{87-101}$ The remaining 53 articles developed QIs for use in 16 other countries 2021 102-145 and 4 other targeted locations (such as the Organisation for Economic Co-operation and Development (OECD) countries) ${ }^{146-152}$ (figure 2). Of the five relevant websites, three were Australian organisations, ${ }^{153-155}$ one was a UK organisation ${ }^{156}$ and the other was USA organisation. ${ }^{157}$ The three Australian and UK organisations developed QIs at the organisation level, while the American website, National Quality Measures Clearinghouse, sponsored by the Agency for Healthcare Research and Quality, stored QIs developed by various countries. Of 7750 QIs listed in the 131 articles and 5 websites, we identified 2431 QIs for RUM: 1947 QIs from journal articles and 484 QIs from the web.

While there were 21 different ways of labelling the measurement tools, 'quality Indicators' $(\mathrm{n}=80,59 \%)$ was the most commonly used term in our included articles 


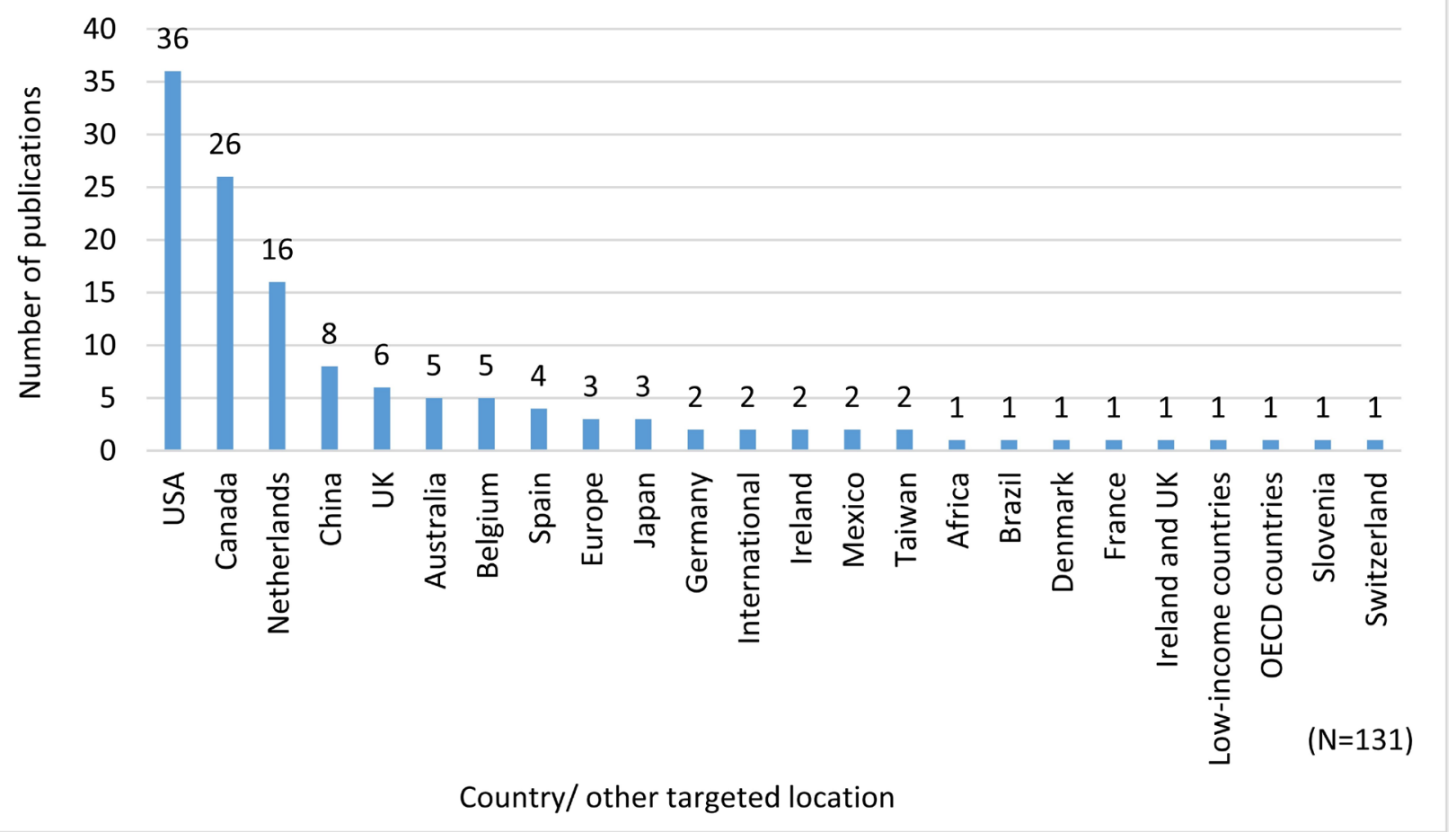

Figure 2 The number of publications by country and other target location.

and websites, followed by 'quality measures' ( $\mathrm{n}=11,8 \%)$, 'quality of care indicators' $(\mathrm{n}=8,6 \%)$ and 'indicators' $(\mathrm{n}=7,5 \%)$.

In terms of the problem type, $43 \%$ of QI sets pertained to disease-based problems ( $\mathrm{n}=89$, eg, knee osteoarthritis), then $27 \%$ for treatment modality-based problems $(n=55$, eg, primary care), $21 \%$ for patient-based problems $(n=44$, eg, geriatric care), $5 \%$ for profession based problems ( $\mathrm{n}=11$, eg, community pharmacists), $3 \%$ generic problems $(\mathrm{n}=6$, eg, long-term prescribing) or $1 \%$ organisation-based practice ( $\mathrm{n}=2$, eg, centralised intake systems). The majority of QIs $(n=2289,94 \%)$ were process indicators, while structure $(n=80)$ and outcome $(n=62)$ indicators accounted for only $3 \%$ each (table 1 ).

Of 2431 QIs, 247 QIs (10\%) were general medication indicators, and 2184 QIs (90\%) were medicine class specific indicators. Some of the 2184 QIs represented more than one ATC code resulting in 2613 first level of ATC classifications. Of these, the most number of QIs covered medicines for nervous system $(\mathrm{N}, \mathrm{n}=407,16 \%)$, followed by the anti-infectives for systemic use (J, $n=397$, $15 \%)$, cardiovascular system $(\mathrm{C}, \mathrm{n}=364,14 \%)$ and blood and blood forming organs ( $\mathrm{B}, \mathrm{n}=345,13 \%$ ) (figure 3). Dermatological medicines (D) were covered by the least number of QIs ( $\mathrm{n}=19,0.7 \%)$ aside from antiparastic products, insecticides and repellents $(\mathrm{P}, \mathrm{n}=7,0.3 \%)$.

The distribution of the QIs across the second level of ATC code and c-DRPs classification system is presented in table 2. General medication indicators were only classified using c-DRPs category. Because some QIs represented more than one ATC code and/or c-DRPs category, the total number of the QIs contained within each cell of the matrix was 3666. Of these, when investigating the number of QIs in each c-DRPs category, the largest number of QIs for 'drug selection' pertained to antibacterials for systemic use (J01, 176 of 2117, 8\%), followed by antithrombotic agents (B01, 172 of 2117, 8\%). Antithrombotic agents (B01) also contributed the largest number of QIs for 'dose selection' (20 of 142, 14\%) and the 'drug use process' (52 of 439, 12\%) and 'monitoring' (52 of 574, 9\%). Likewise, the most number of QIs for 'treatment duration' (13 of 85, 15\%) pertained to psychoanaleptics (N06).

With regard to the c-DRPs classification system, the most common c-DRPs pertained to 'drug selection' $(\mathrm{n}=2117,58 \%)$, followed by 'monitoring' $(\mathrm{n}=574,16 \%)$ and the 'drug use process' $(\mathrm{n}=439,12 \%)$. The remaining six c-DRPs categories accounted for only $14 \%$ of the QIs. Interestingly, only QIs for analgesics (N02) covered all nine c-DRPs categories. In terms of general medication indicators, the largest number of QIs covered 'Logistics' $(\mathrm{n}=73,29 \%)$ among the c-DRPs category, which mainly focus on medication reconciliation problems during transitions of care, such as hospital admission and discharge.

A complete list of 2431 QIs is available in online supplementary table $\mathrm{S} 7$.

\section{DISCUSSION}

The RUM is important for almost every healthcare setting in every country across the globe. Knowledge of whether medicines are being used in an optimal manner therefore presents a significant international challenge. In this systematic review, we identified 2431 QIs evaluating RUM 

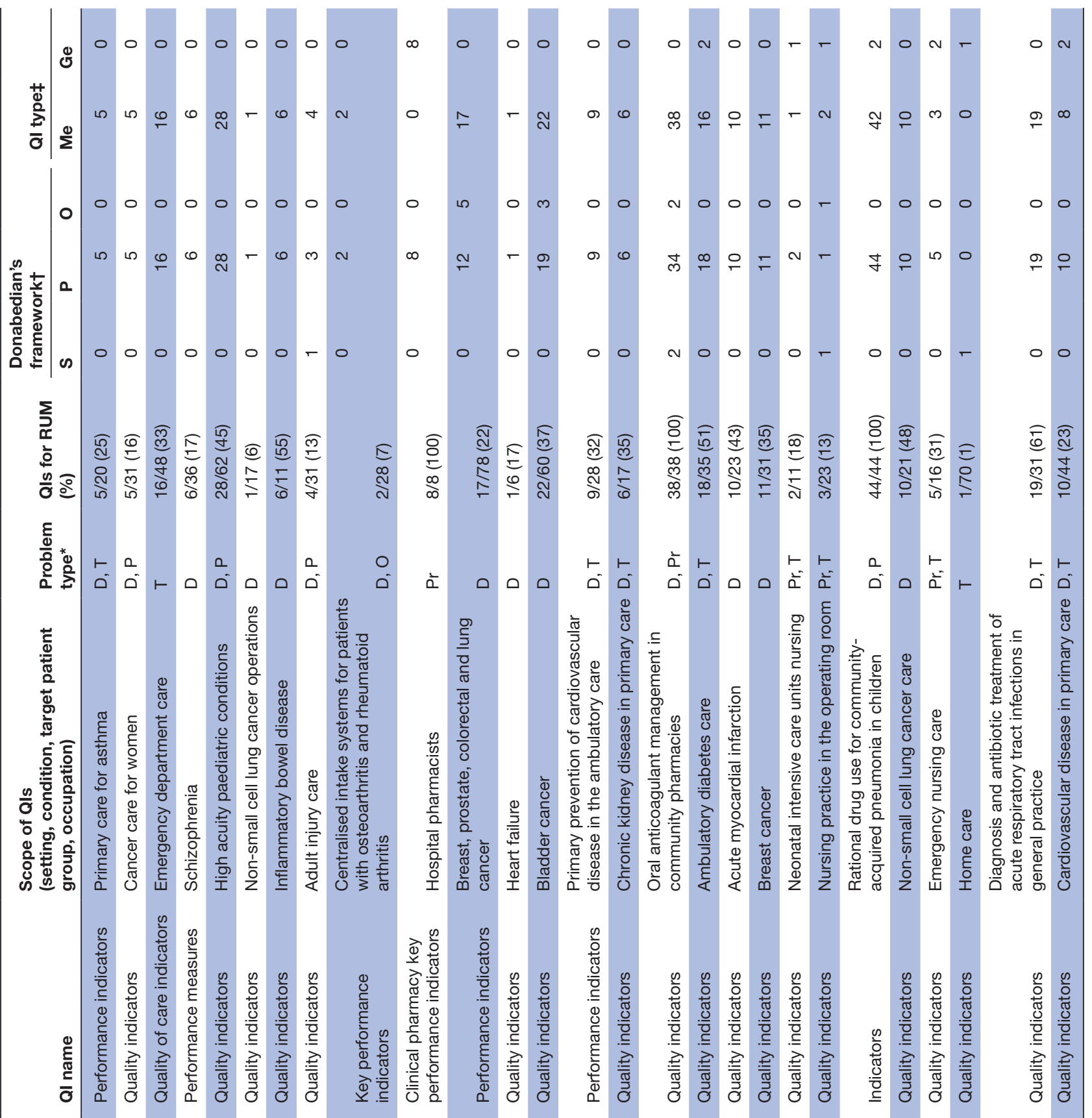

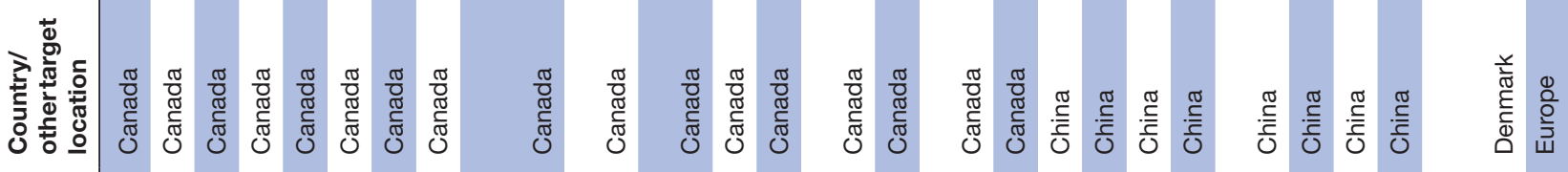

离
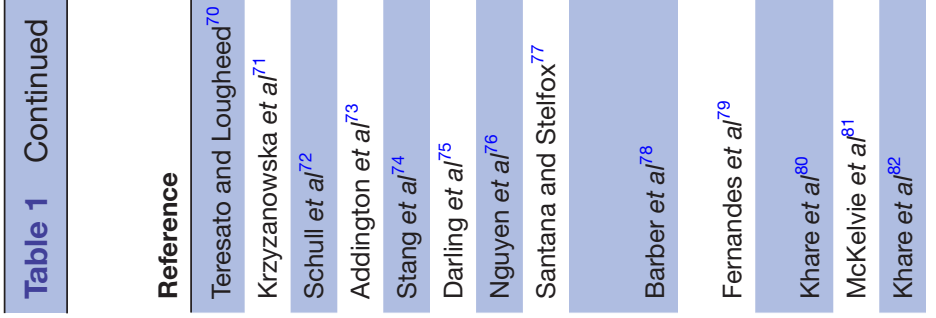

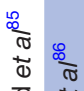

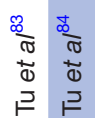

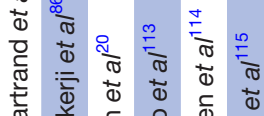




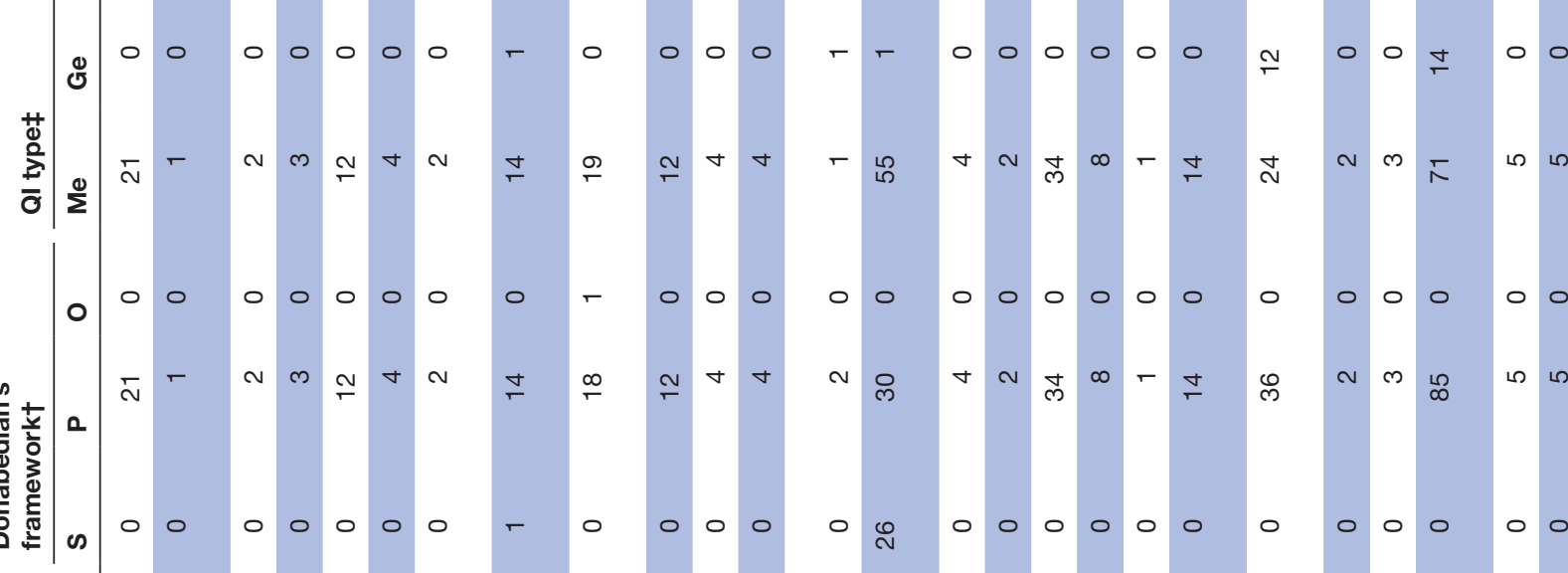

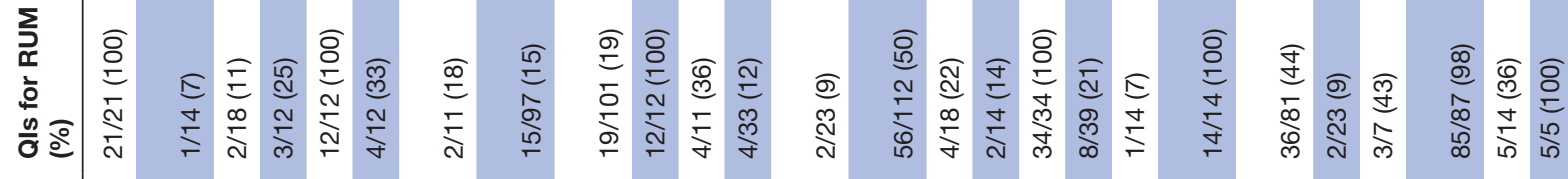

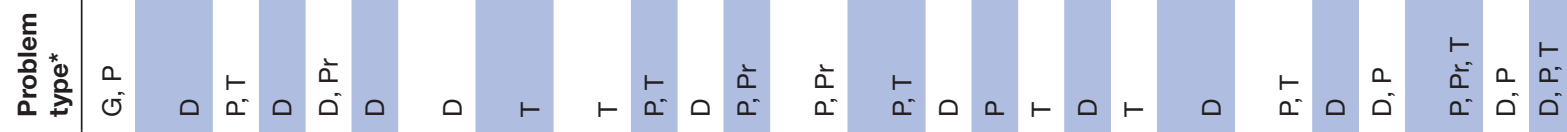

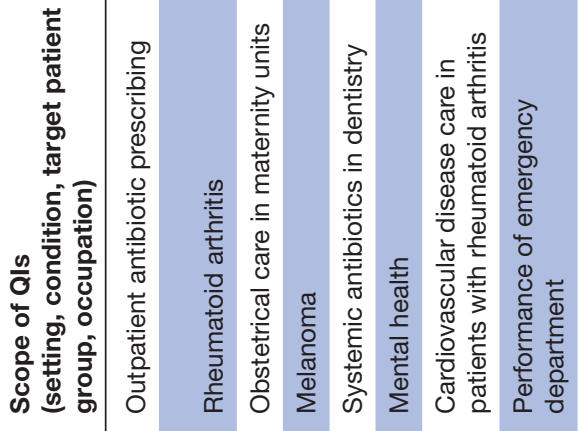

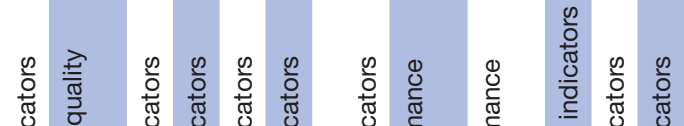

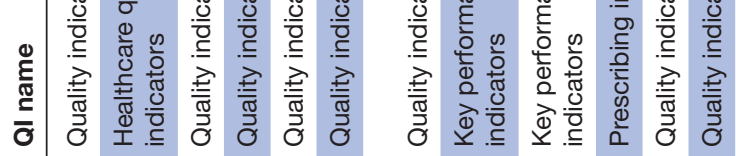

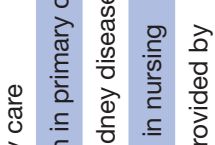

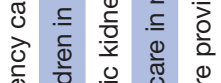

离

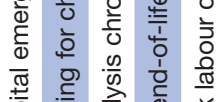

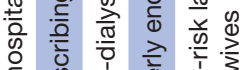

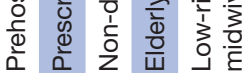




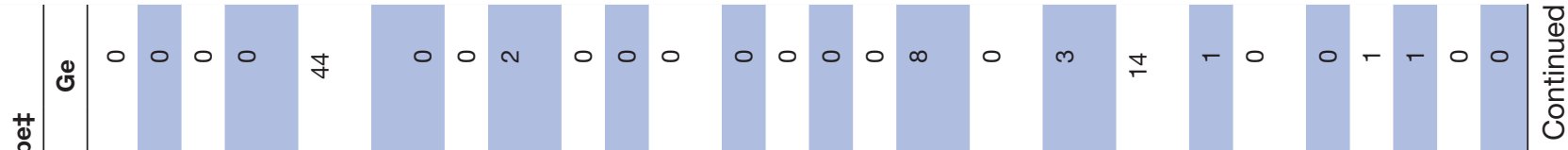

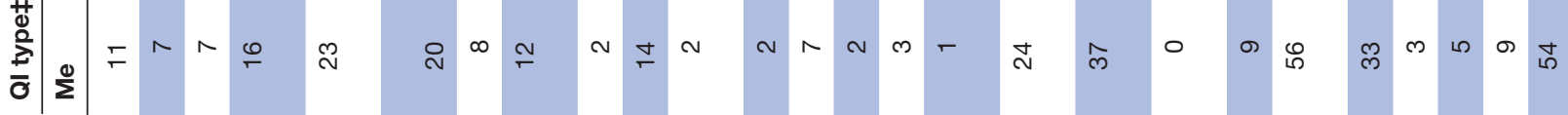

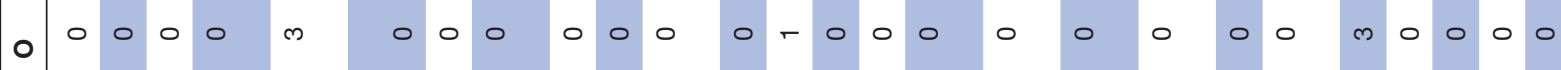

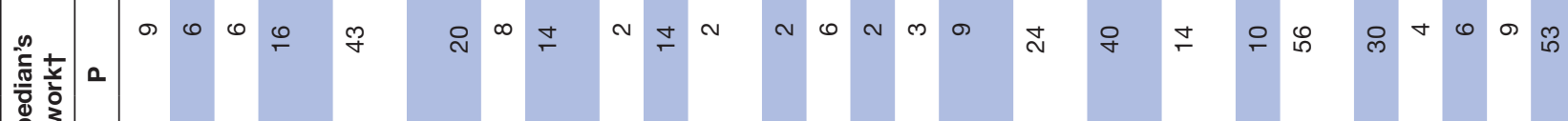

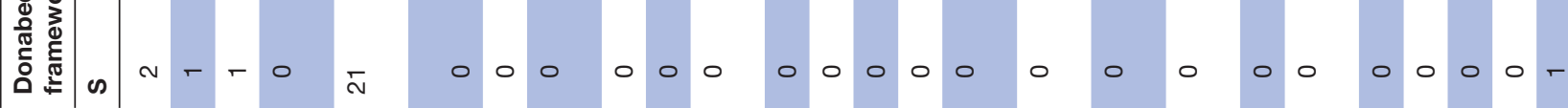

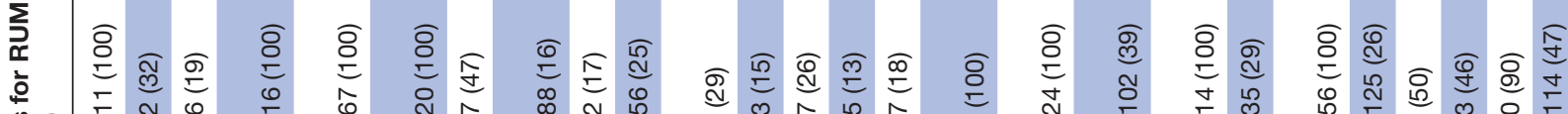

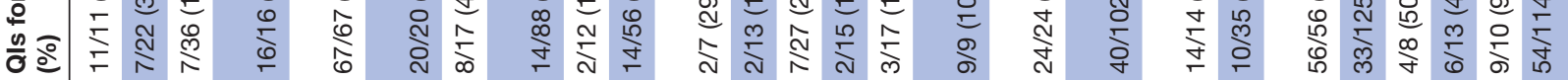

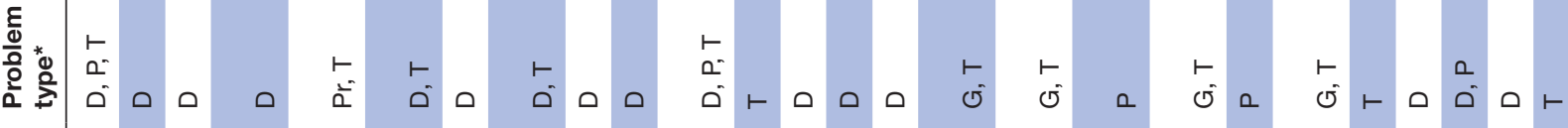

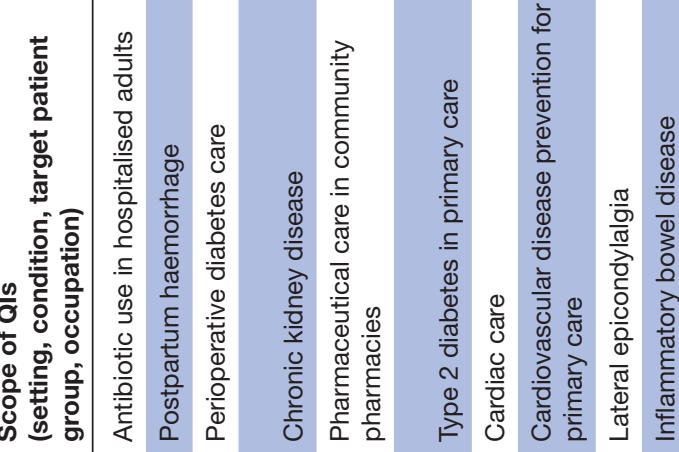

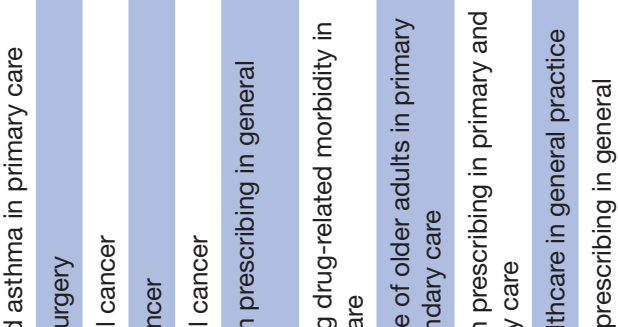

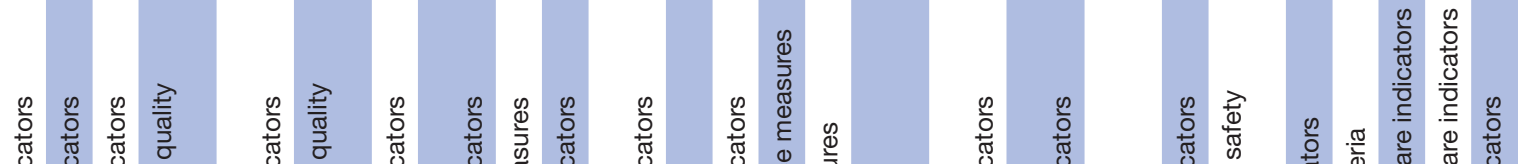

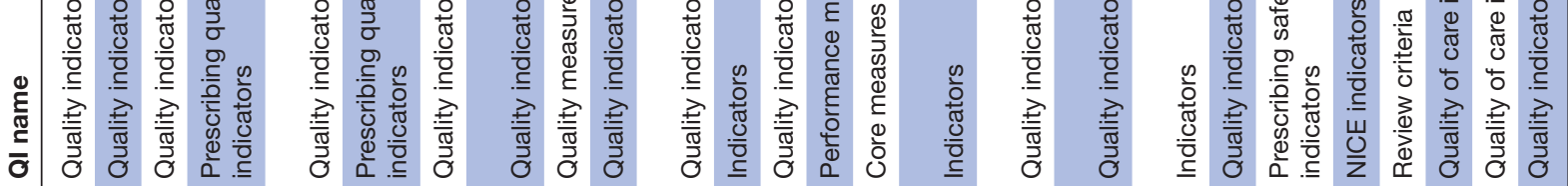

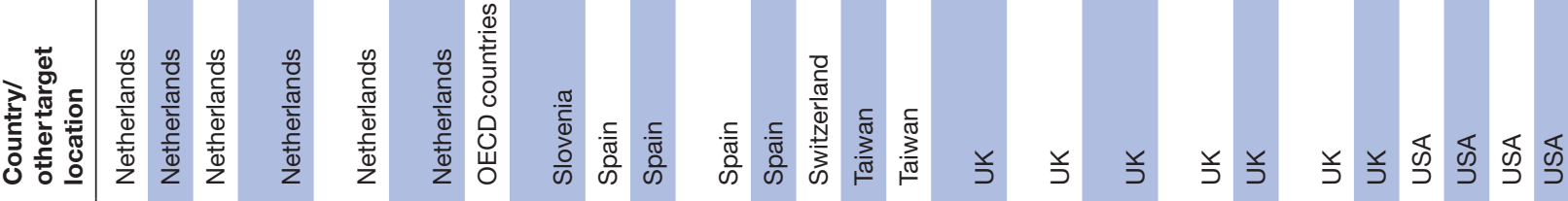

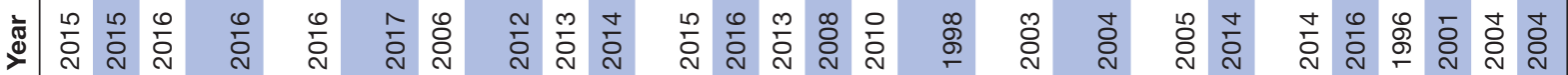




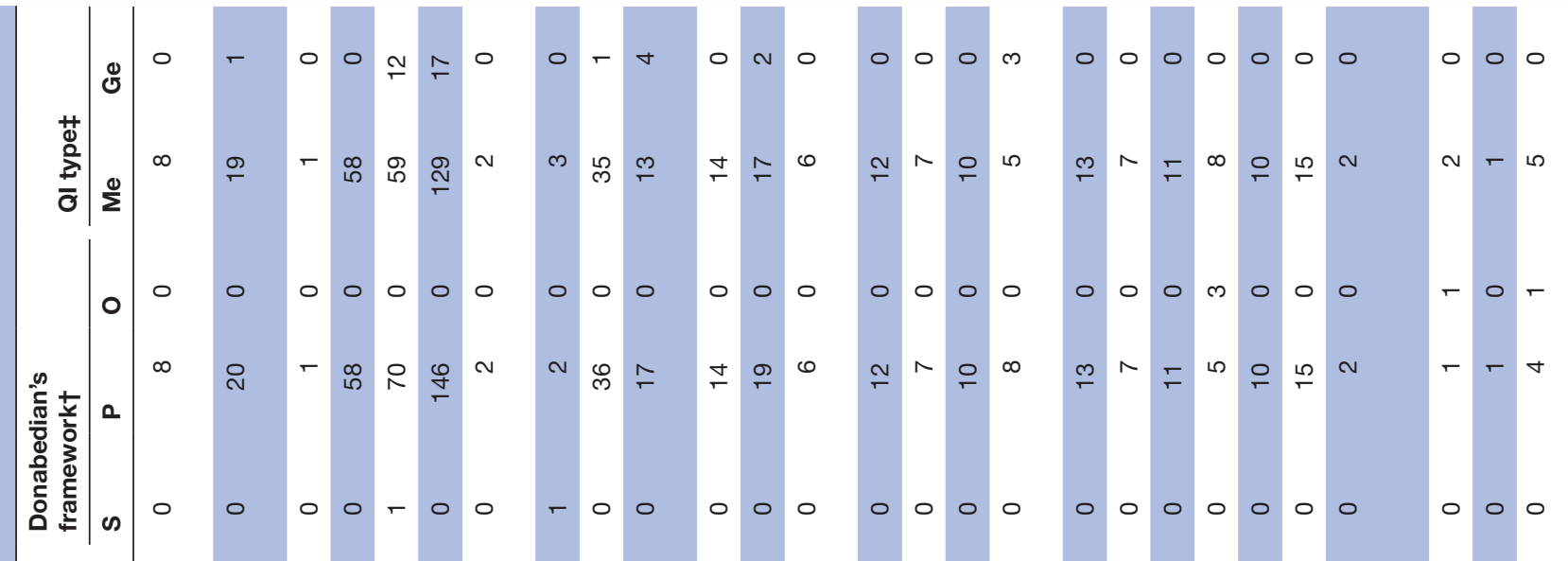

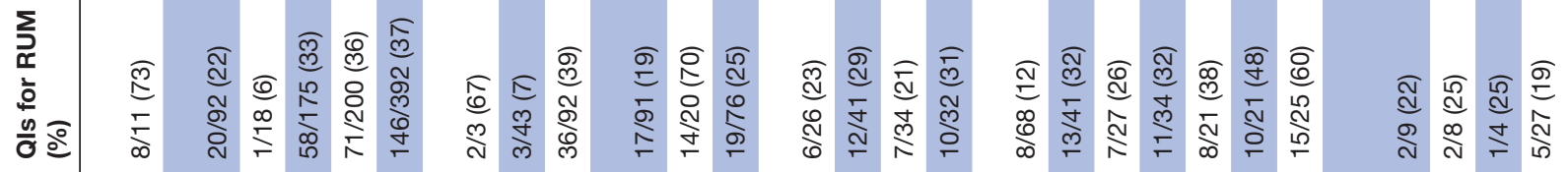

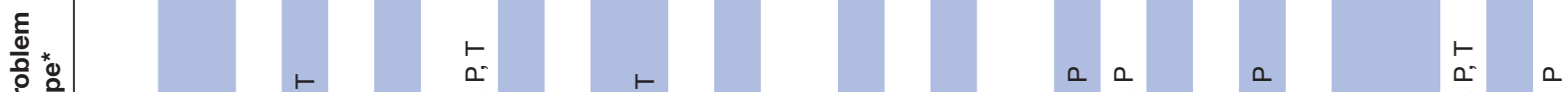

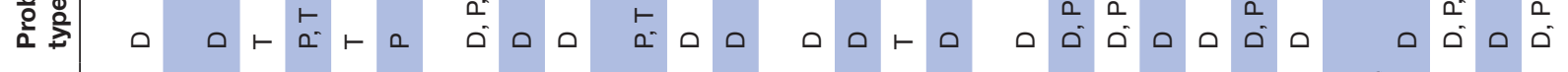

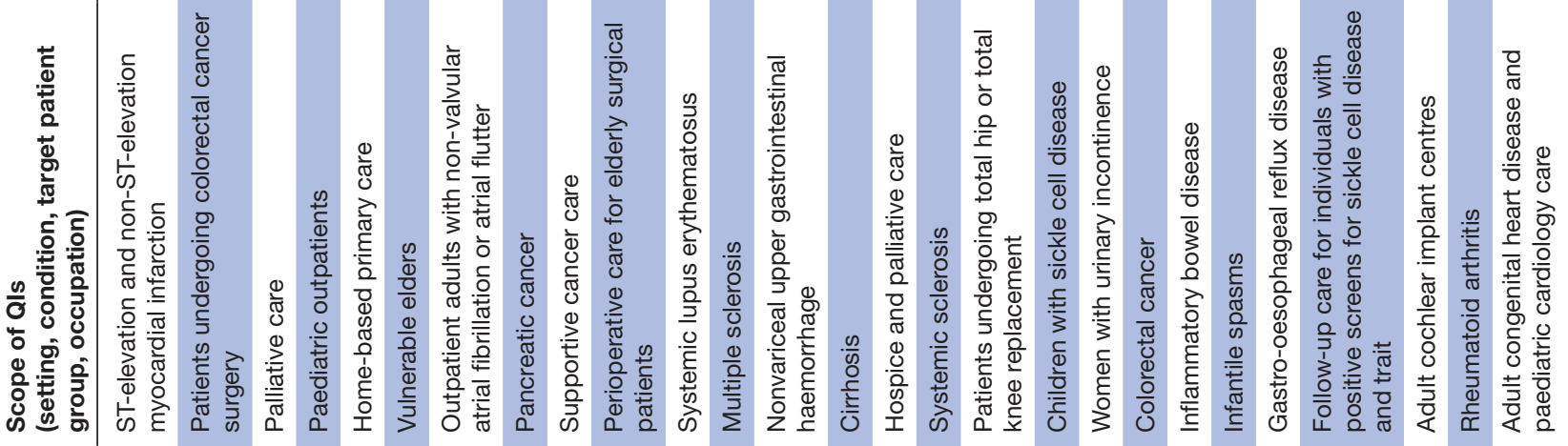

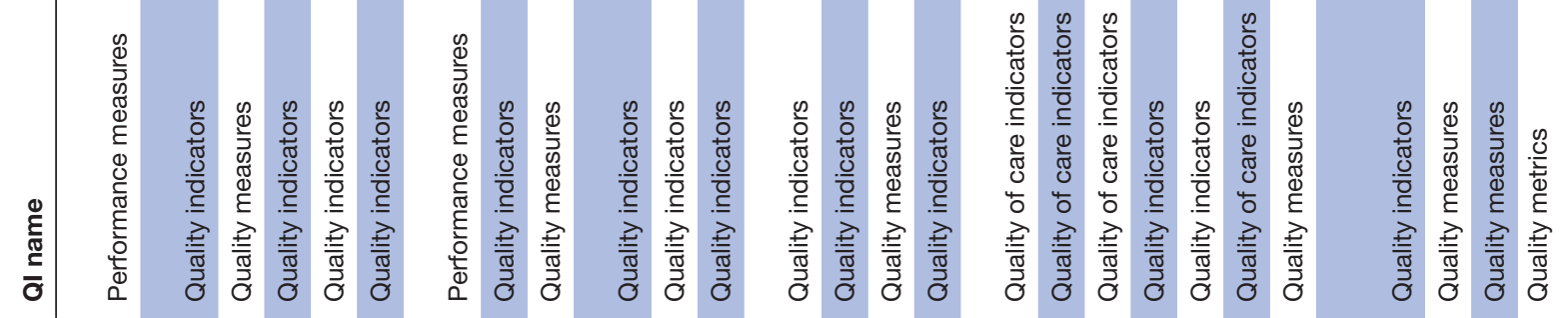

范

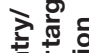

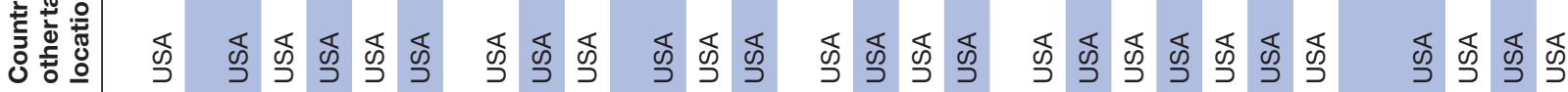

ঠ 


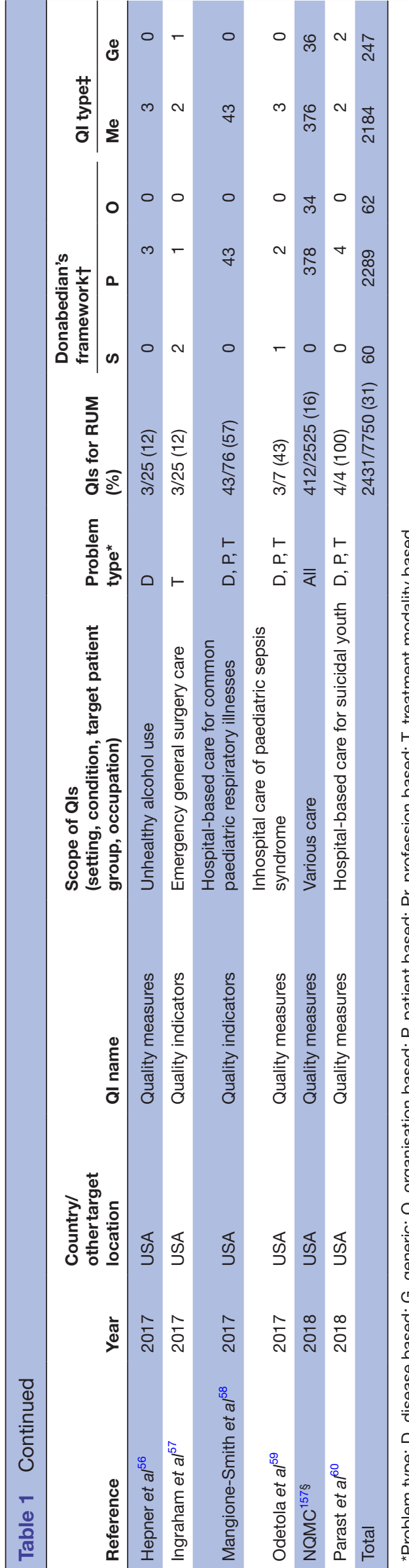

and classified them using multiple frameworks. The large number of QIs reflects the multidimensional components of RUM and the different perspectives of multidisciplinary stakeholders involved in the RUM. The QI list presented in this review can be used as a comprehensive database and reference for existing content validated QIs pertaining to RUM. All stakeholders involved in quality assurance for RUM, for example, healthcare professionals, researchers and decision makers, can select QIs from the multicategorised QI list for their own purpose. Since healthcare systems and medication guidelines may vary between countries when using the QIs at the local setting, it is important for users to critically review the QIs for their acceptability, feasibility of acquiring necessary data, reliability, sensitivity to change, work load and validity. ${ }^{814}$

The vast majority of the QIs for RUM identified were intended to be used in only a few high-income countries. Low-income and middle-income countries, however, are estimated to have similar rates of medication-related adverse events, and the impact has been reported to be about twice as much in terms of the number of years of healthy life lost. ${ }^{4}$ Since feasibility of data collection for calculating QI scores in low-income settings remain a concern, ${ }^{151}$ further efforts for improving the data collection method might need to be made. We found that even though the role of all measurement tools (ie, QIs) relevant to RUM have the goal of quality improvement, the terminology used to describe QIs varied significantly. About 20 name variations were found, which reflects the absence of a universally accepted definition for such tools. For example, Campbell et al distinguished QIs from performance indicators, arguing that QIs infer a judgement about the quality of care provided, while performance indicators are statistical devices for monitoring care provided to populations without any necessary inference about quality. However, we found that these terms, 'quality' and 'performance', were used interchangeably. Hence, further research for standardising the definition that distinguishes these measurement tools is warranted.

We also found a significant gap in terms of the problem type (eg, 'disease-based problems' (43\%), 'treatment modality-based problems' (27\%) and 'profession-based problems' (5\%)). Since RUM is facilitated by collaboration in multidisciplinary teams, all healthcare professionals involved in medication treatment should take responsibility for quality assurance, regardless of diseases, care settings and professions. When using Donabedian's framework, about $94 \%$ of the identified QIs related to processes of care. This could be because processes of care are easier to measure, and because process indicators can provide interpretable feedback about care provided. ${ }^{158}$ In contrast, there was a paucity of outcome indicators. This may be because multiple factors influence health outcomes, many of which are outside the control of individual healthcare professionals. In addition, the difficulty of obtaining sufficient information for assessing outcomes, requiring the linkage of multiple data sources, 


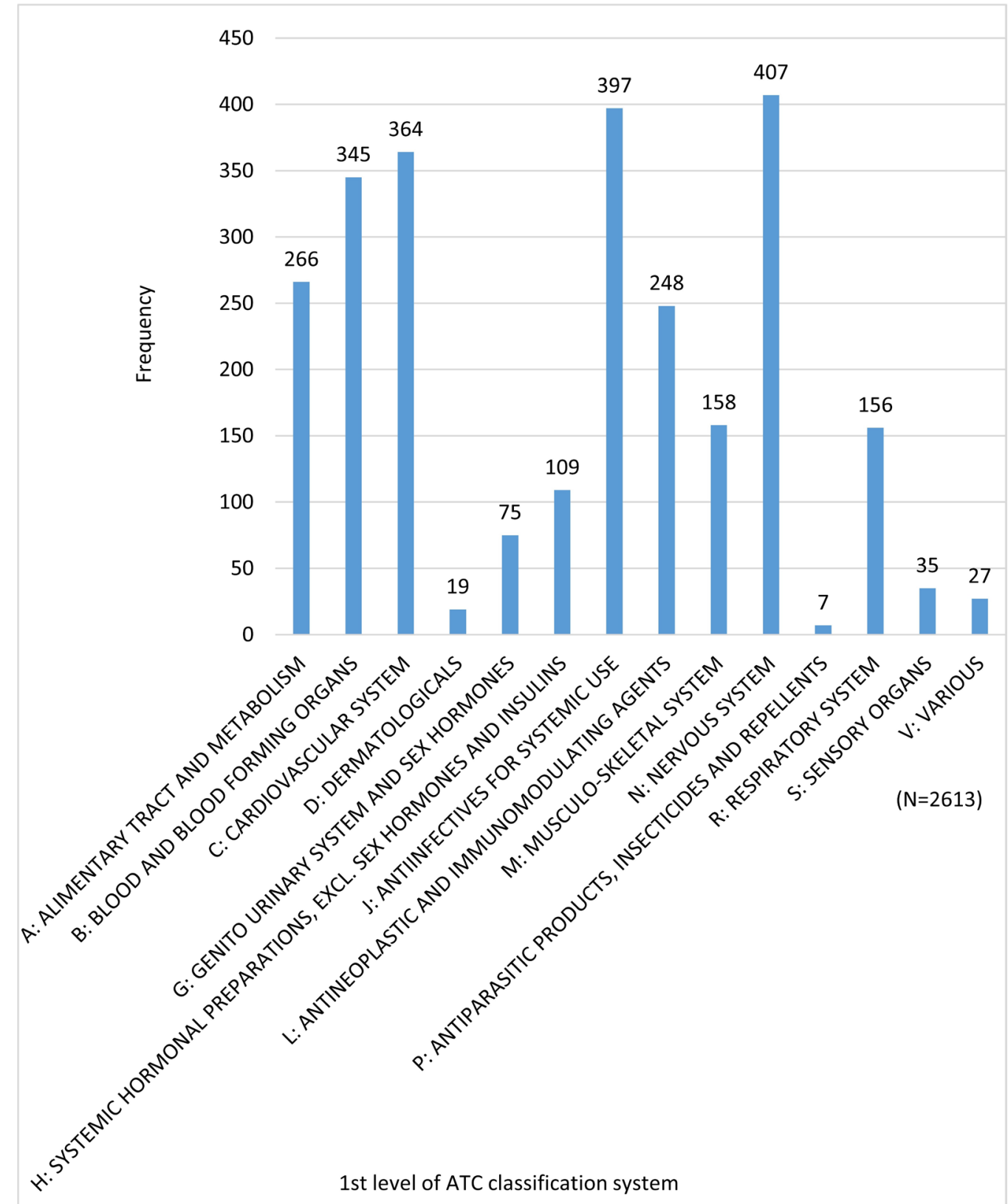

Figure 3 The number of QIs by first-level ATC code. ATC, Anatomical Therapeutic Chemical; Qls, quality indicators.

could be another reason of the limited number of outcome indicators. For outcome indicators to become more useful, multiple confounders such as patient demographic characteristics, and severity of illness, may need to be considered. ${ }^{159}$ Similarly, there was a low proportion of structural indicators. This may be because they are not sufficiently sensitive for monitoring ongoing performance and they have traditionally been used to monitor standards of healthcare facilities, not RUM. ${ }^{160}$ It is noteworthy that there is no set requirement for equal proportions of structural, process and outcome indicators in quality measurement. Instead, it is important to recognise the interconnectedness of these measures. For example, high structure indicator scores increase the likelihood of good process indicator scores, which in turn, may lead to higher outcome indicator scores. ${ }^{161}$ Further research is needed to investigate the associations between the identified QIs in each framework within healthcare settings.

We found large differences in the degree to which c-DRPs categories were covered by the identified QIs. Not surprisingly, 'Drug selection' accounted for more than half of the QIs, as choosing an inappropriate drug is the main cause of DRPs. ${ }^{3162}$ Since focusing on limited c-DRPs categories may divert attention and resources away from other factors contributing to DRPs, ${ }^{163} 164$ users of QIs should be aware of what c-DRPs categories are not being measured. Like Donabedian's framework, we do not expect that QIs should be evenly distributed across each of the c-DRPs categories or ATC groups. We do, however, expect that there will be greater QIs in areas of greatest need. These clinical areas may include common areas of practice suspected to be associated with inappropriate 


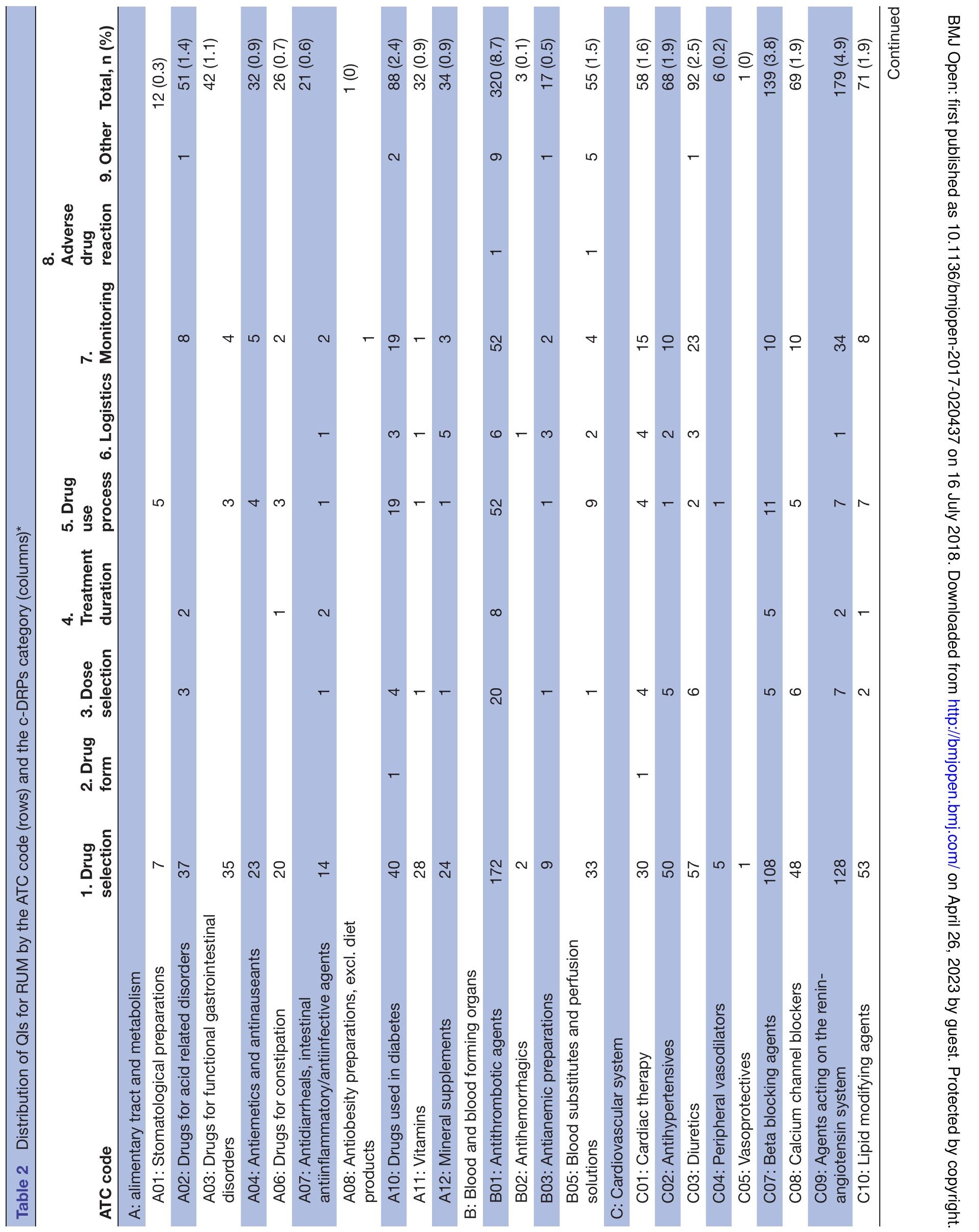




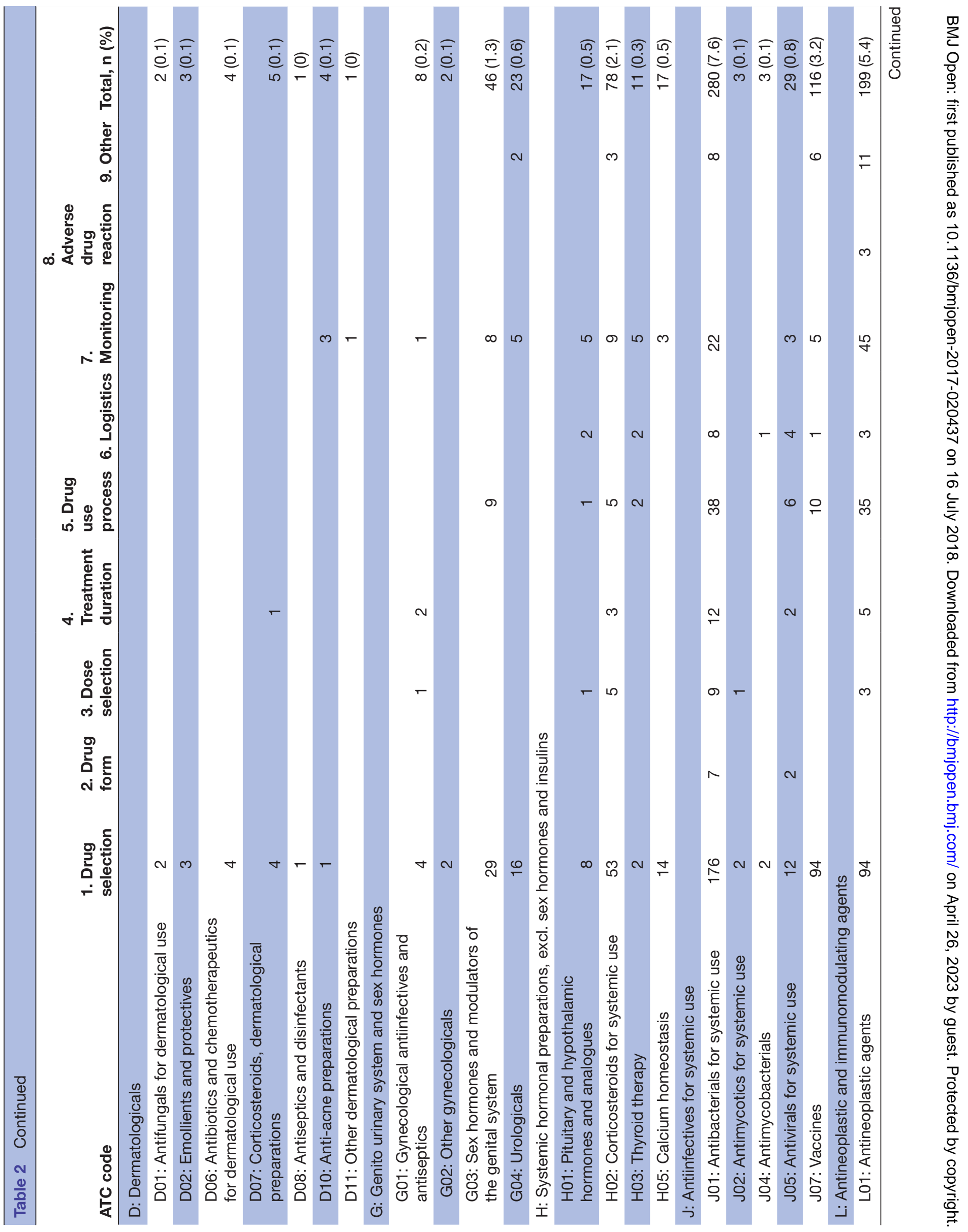




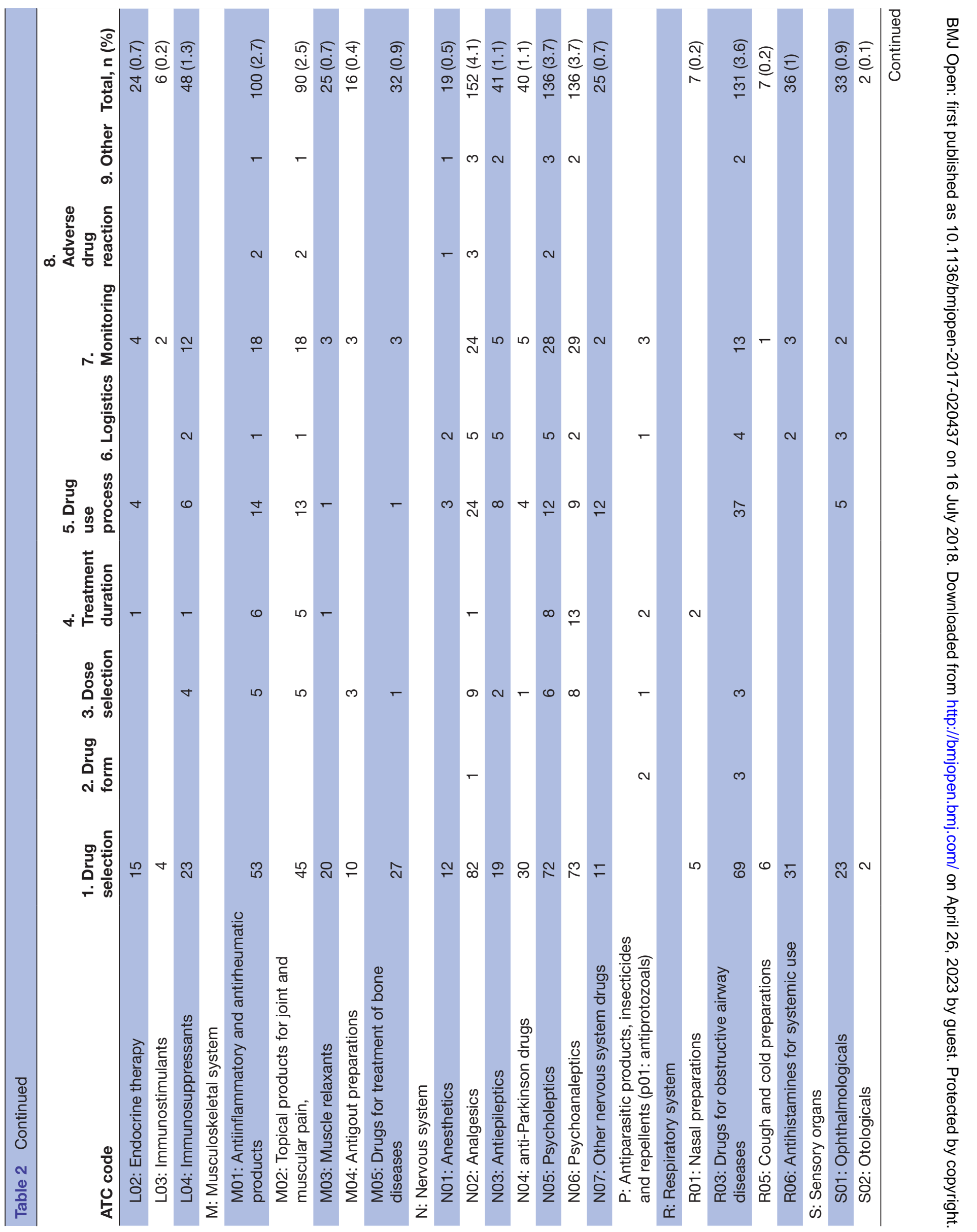


use of medicines and significant economic burden (eg, over use of antibiotics for upper respiratory tract infection and overuse of opioid analgesics). Use of QIs in these areas may fill the evidence-practice gaps and minimise subsequent DRPs. ${ }^{165} 166$

QIs for antithrombotic agents (B01) accounted for the larger proportion of QIs targeting 'drug selection', 'dose selection', 'drug use process' and 'monitoring' in c-DRPs categories. This may be explained by the fact that the majority of preventable drug-related admissions have been attributed to antiplatelets and anticoagulants, which have narrow therapeutic indices and high risk of overdose or toxicity, ${ }^{3}$ and also the fact that medication adherence to long-term antithrombotic therapy remains challenging. ${ }^{167}$ Likewise, QIs for psychoanaleptics (N06) accounted for the largest part of QIs targeting 'treatment duration'. Since medication adherence is an ongoing challenge for consumers being treated for depression with antidepressant therapy, it seems appropriate that a relatively large number of QIs have been developed in these categories. In contrast, there were few QIs for some ATC groups, such as dermatological medicines. This has previously been reported in the literature for QIs as a whole, when comparing the scope of dermatology QIs to other medical specialty areas (eg, internal medicine, paediatrics or cardiology). ${ }^{168}$ This may be because dermatological medicines, especially topical agents, are relatively less harmful and less expensive. Since irrational topical dermatological medication can occur because of drug selection error and patients' misunderstanding, prescribing, dispensing and administration errors, ${ }^{169}$ more QIs targeting the wide range of c-DRPs categories may need to be developed for ensuring RUM. Furthermore, when focusing on general medication indicators, QIs largely focused on 'logistic' issues such as medication reconciliation at transition points and unavailability of medicines in the c-DRPs category. This differed from medicine class specific QIs, which mainly focused on 'drug selection' issues. These differences underscore the importance of the combined use of general medication QIs and medicine class specific QIs for the comprehensive evaluation of RUM.

In terms of interpretation of direction of QI scores, we found different methods of scoring: those for evaluating whether necessary or appropriate care was provided and those for evaluating whether unnecessary or inappropriate care was provided. Therefore, care in the interpretation of QI scores is recommended as they have different interpretations based on positively or negatively worded indicators. We also found there were many similar QIs, with only minor differences in wording or definition. These slight differences may be attributed to feasibility of acquiring the data, differences in national guidelines, targeted populations or healthcare systems between locations or countries. However, these minor differences could adversely affect comparability of QI scores and could decrease motivation of healthcare professionals to participate in initiatives if 
they feel they are being asked the same indicator questions repeatedly. This may be overcome by undertaking a mapping exercise of the QIs identified in our review, with the potential of aggregating some of the QIs. QI is one of the measurement tools to evaluate quality of care at the healthcare facility or group level. QI scores do not directly represent quality of individual patient care but are used as 'flags' or 'alerts' to potential problems that require further analysis. ${ }^{170} \mathrm{In}$ addition, actions required for quality improvement vary from the level of individual patients, healthcare providers, facilities or healthcare system. Therefore, a multidisciplinary, multilevel quality improvement initiative is needed for comprehensive quality assurance.

\section{Strengths and limitations}

Our review has some notable strengths. This is the first comprehensive review of QIs pertaining to RUM without restriction of disease categories and care settings. In order to do this, a comprehensive literature search was undertaken across multiple databases and websites. Moreover, the classification of QIs was based on multiple frameworks (eg, Donabedian and c-DRPs) for maximum understanding and profiling of the included QIs. The rich dataset of identified QIs can be used as a starting point for healthcare professionals, researchers, decision makers and others, for identifying and selecting existing QIs for the evaluation of RUM. We also identified significant gaps in current quality measurements in each framework, underscoring the need for further QI development in some areas. We do however acknowledge that our approach has some limitations. First, we only included QIs that were developed using consensus methods and excluded QIs if consensus results for QI development were unclear. Therefore, we might have excluded valid indicators during the screening process. Second, although 5\% of this review processes were verified by multiple authors, our mapping exercise into the classification system may be viewed as subjective. Third, we identified QIs developed using consensus methods to ensure content validity; however, the methodological rigour of each study was not assessed. Therefore, the quality of the content validity of identified QIs was not reported.

\section{Conclusions}

Overall, by using multiple frameworks, we were able to identify and classify 2431 QIs covering different constructs of RUM. However, this review also pointed to some significant gaps in current quality measurements, making it difficult for healthcare systems to fully assess whether RUM has been achieved or not. The list of the identified QIs can be used as a database for evaluating the achievement of RUM. All stakeholders involved in quality assurance for RUM can select QIs from the multicategorised QI list for their own purpose. In order to more effectively evaluate the extent to which RUM has been achieved, further development and validation of QIs may be required.
Contributors KF developed the review protocol and designed the review questions, carried out database search, articles screening, data extraction and classification and manuscript write up. RJM participated in protocol development, database search, articles screening, data extraction and classification and manuscript review. TFC participated in protocol development, conceptualising the review, designing review questions and database search, article screening, data extraction and classification and manuscript review.

Funding This research received no specific grant from any funding agency in the public, commercial or not-for-profit sectors.

Competing interests None declared.

Patient consent Not required.

Provenance and peer review Not commissioned; externally peer reviewed.

Data sharing statement Further details on studies included in this review can be retrieved by contacting the corresponding author.

Open access This is an open access article distributed in accordance with the Creative Commons Attribution Non Commercial (CC BY-NC 4.0) license, which permits others to distribute, remix, adapt, build upon this work non-commercially, and license their derivative works on different terms, provided the original work is properly cited, appropriate credit is given, any changes made indicated, and the use is non-commercial. See: http://creativecommons.org/licenses/by-nc/4.0/.

\section{REFERENCES}

1. World Health Organization. The pursuit of responsible use of medicines: sharing and learning from country experiences: Geneva: World Health Organization. 2012 http://www.who.int/medicines/ publications/responsible_use/en/ (accessed 15 May 2017).

2. World Health Organization. Dept. of essential drugs and medicines policy. Promoting rational use of medicines: core components: Geneva: World Health Organization 2002 http://www.who.int/iris/ handle/10665/67438 (accessed 5 May 2017).

3. Howard RL, Avery AJ, Slavenburg S, et al. Which drugs cause preventable admissions to hospital? A systematic review. Br J Clin Pharmacol 2007;63:136-47.

4. World Health Organization. WHO launches global effort to halve medication-related errors in 5 years: Geneva: World Health Organization. 2017 http://www.who.int/mediacentre/news/releases/ 2017/medication-related-errors/en/ (accessed 5 May 2017).

5. Mainz J. Defining and classifying clinical indicators for quality improvement. Int J Qual Health Care 2003;15:523-30.

6. Brook RH, McGlynn EA, Shekelle PG. Defining and measuring quality of care: a perspective from US researchers. Int $J$ Qual Health Care 2000;12:281-95.

7. McGlynn E, Asch SM. Developing a clinical performance measure. Am J Prev Med 1998;14:14-21.

8. Campbell SM, et al. Improving the quality of health care: Research methods used in developing and applying quality indicators in primary care. BMJ 2003;326:816-9.

9. Smeulers M, Verweij L, Maaskant JM, et al. Quality indicators for safe medication preparation and administration: a systematic review. PLoS One 2015;10:e0122695.

10. Catumbela E, Certal V, Freitas A, et al. Definition of a core set of quality indicators for the assessment of HIV/AIDS clinical care: a systematic review. BMC Health Serv Res 2013;13:236.

11. Sadeghi BH, Farhoudi M, Hajebrahimi S, et al. A systematic review on clinical indicators, their types and codification processes. Journal of Clinical Research \& Governance 2015;4:1-9.

12. Copnell B, Hagger V, Wilson SG, et al. Measuring the quality of hospital care: an inventory of indicators. Intern Med J 2009;39:352-60.

13. Moher D, Liberati A, Tetzlaff J, et al. PRISMA Group. Preferred reporting items for systematic reviews and meta-analyses: the PRISMA statement. Ann Intern Med 2009;151:264-9.

14. Campbell SM, Braspenning J, Hutchinson A, et al. Research methods used in developing and applying quality indicators in primary care. Qual Saf Health Care 2002;11:358-64.

15. Klassen A, Miller A, Anderson N, et al. Performance measurement and improvement frameworks in health, education and social services systems: a systematic review. International Journal for Quality in Health Care 2010;22:44-69.

16. Haller G. Quality and safety indicators in anesthesia: a systematic review. Anesthesiology 2009;110:1158-75.

17. Alessandrini E, Varadarajan K, Alpern ER, et al. Pediatric Emergency Care Applied Research Network. Emergency department quality: 
an analysis of existing pediatric measures. Acad Emerg Med 2011:18:519-26.

18. Evans SM, Lowinger JS, Sprivulis PC, et al. Prioritizing quality indicator development across the healthcare system: identifying what to measure. Intern Med J 2009;39:648-54.

19. Donabedian A. The definition of quality and approaches to its assessment. Ann Arbor, Mich: Health Administration Press, 1980.

20. Sun H, Liu M, Hou S. Quality indicators for acute myocardial infarction care in China. Int J Qual Health Care 2011;23:365-74.

21. Tropea J, Amatya B, Brand CA. Use of consensus methods to select clinical indicators to assess activities to minimise functional decline among older hospitalised patients. Aust Health Rev 2011;35:404-11.

22. World Health Organization. The Anatomical Therapeutic Chemical (ATC) classification system: structure and principles. Geneva: World Health Organization, 2011. https://www.whocc.no/atc/structure and_principles/. (accessed 5 May 2017).

23. Teichert M, Schoenmakers T, Kylstra N, et al. Quality indicators for pharmaceutical care: a comprehensive set with national scores for Dutch community pharmacies. Int J Clin Pharm 2016;38:870-9.

24. Basger BJ, Moles RJ, Chen TF. Development of an Aggregated System for Classifying Causes of Drug-Related Problems. Ann Pharmacother 2015;49:405-18.

25. Hadorn DC, Baker DW, Kamberg CJ, et al. Phase II of the AHCPR-sponsored heart failure guideline: translating practice recommendations into review criteria. Jt Comm J Qual Improv 1996;22:265-76.

26. Asch SM, Kerr EA, Lapuerta P, et al. A new approach for measuring quality of care for women with hypertension. Arch Intern Med 2001;161:1329-35.

27. Mikuls TR, MacLean $\mathrm{CH}$, Olivieri J, et al. Quality of care indicators for gout management. Arthritis \& Rheumatism 2004:50:937-43.

28. Saliba D, Solomon D, Rubenstein L, et al. Quality Indicators for the Management of Medical Conditions in Nursing Home Residents. $J$ Am Med Dir Assoc 2004;5:297-309.

29. Krumholz HM, Anderson JL, Brooks NH, et al. ACC/AHA clinical performance measures for adults with ST-elevation and non-STelevation myocardial infarction: a report of the American College of Cardiology/American Heart Association Task Force on Performance Measures (Writing Committee to Develop Performance Measures on ST-Elevation and Non-ST-Elevation Myocardial Infarction). Circulation 2006;113:732-61.

30. McGory ML, Shekelle PG, Ko CY. Development of quality indicators for patients undergoing colorectal cancer surgery. J Natl Cancer Inst 2006;98:1623-33

31. Mularski RA, Curtis JR, Billings JA, et al. Proposed quality measures for palliative care in the critically ill: a consensus from the robert wood johnson foundation critical care workgroup. Crit Care Med 2006;34:S404-S411.

32. Mangione-Smith R, DeCristofaro AH, Setodji CM, et al. The Quality of ambulatory care delivered to children in the United States. N Engl J Med Overseas Ed 2007;357:1515-23.

33. Smith KL, Soriano TA, Boal J. Brief communication: National quality-of-care standards in home-based primary care. Ann Intern Med 2007;146:188-92.

34. Wenger NS, Roth CP, Shekelle P, et al. Introduction to the assessing care of vulnerable elders-3 quality indicator measurement set. J Am Geriatr Soc 2007;55 Suppl 2:S247-S252.

35. Estes NA, Halperin JL, Calkins $\mathrm{H}$, et al. ACC/AHA/Physician Consortium 2008 clinical performance measures for adults with nonvalvular atrial fibrillation or atrial flutter: a report of the American College of Cardiology/American Heart Association Task Force on Performance Measures and the Physician Consortium for Performance Improvement (Writing Committee to Develop Clinical Performance Measures for Atrial Fibrillation): developed in collaboration with the Heart Rhythm Society. Circulation 2008:117:1101-20.

36. Bilimoria KY, Bentrem DJ, Lillemoe KD, et al. Assessment of pancreatic cancer care in the United States based on formally developed quality indicators. J Natl Cancer Inst 2009;101:848-59.

37. Lorenz KA, Dy SM, Naeim A, et al. Quality Measures for Supportive Cancer Care: The Cancer Quality-ASSIST Project. J Pain Symptom Manage 2009;37:943-64

38. McGory ML, Kao KK, Shekelle PG, et al. Developing quality indicators for elderly surgical patients. Ann Surg 2009;250:338-47.

39. Yazdany J, Panopalis P, Gillis JZ, et al. A quality indicator set for systemic lupus erythematosus. Arthritis \& Rheumatism 2009;61:370-7.

40. Cheng EM, Crandall CJ, Bever CT, et al. Quality indicators for multiple sclerosis. Mult Scler 2010;16:970-80.
41. Kanwal F, Barkun A, Gralnek IM, et al. Measuring quality of care in patients with nonvariceal upper gastrointestinal hemorrhage: development of an explicit quality indicator set. Am J Gastroenterol 2010;105:1710-8

42. Kanwal F, Kramer J, Asch SM, et al. An explicit quality indicator set for measurement of quality of care in patients with cirrhosis. Clin Gastroenterol Hepatol 2010;8:709-17.

43. Schenck AP, Rokoske FS, Durham DD, et al. The PEACE Project: identification of quality measures for hospice and palliative care. $J$ Palliat Med 2010;13:1451-9.

44. Khanna D, Kowal-Bielecka O, Khanna PP, et al. Quality indicator set for systemic sclerosis. Clinical and Experimental Rheumatology 2011;29:S33-9.

45. SooHoo NF, Lieberman JR, Farng E, et al. Development of quality of care indicators for patients undergoing total hip or total knee replacement. BMJ Qual Saf 2011;20:153-7.

46. Wang CJ, Kavanagh PL, Little AA, et al. Quality-of-care indicators for children with sickle cell disease. Pediatrics 2011;128:484-93.

47. Anger JT, Scott VC, Kiyosaki K, et al. Development of quality indicators for women with urinary incontinence. Neurourol Urodyn 2013;32:1058-63.

48. Jackson GL, Zullig LL, Zafar SY, et al. Using NCCN clinical practice guidelines in oncology to measure the quality of colorectal cancer care in the veterans health administration. $J$ Nat/ Compr Canc Netw 2013:11:431-41.

49. Melmed GY, Siegel CA, Spiegel BM, et al. Quality indicators for inflammatory bowel disease: development of process and outcome measures. Erratum appears in Inflamm Bowel Dis. Inflamm Bowel Dis 2013;19:662-8.

50. Wang CJ, Jonas R, Fu CM, et al. Quality-of-care indicators for infantile spasms. J Child Neurol 2013;28:13-20.

51. Yadlapati R, Gawron AJ, Bilimoria K, et al. Development of quality measures for the care of patients with gastroesophageal reflux disease. Clin Gastroenterol Hepatol 2015;13:874-83.

52. Faro EZ, Wang CJ, Oyeku SO. Quality indicator development for positive screen follow-up for sickle cell disease and trait. Am J Prev Med 2016;51:S48-S54.

53. Vila PM, Lieu JEC, Hullar TE, et al. Developing quality measures for adult cochlear implant centers: preliminary findings. Otolaryngology-Head \& Neck Surgery 2016;155:748-52.

54. Yazdany J, Robbins M, Schmajuk G, et al. Development of the american college of rheumatology's rheumatoid arthritis electronic clinical quality measures. Arthritis Care Res 2016;68:1579-90.

55. Chowdhury D, Gurvitz M, Marelli A, et al. Development of quality metrics in ambulatory pediatric cardiology. J Am Coll Cardiol 2017:69:541-55.

56. Hepner KA, Watkins KE, Farmer CM, et al. Quality of care measures for the management of unhealthy alcohol use. $J$ Subst Abuse Treat 2017;76:11-17.

57. Ingraham A, Nathens A, Peitzman A, et al. Assessment of emergency general surgery care based on formally developed quality indicators. Surgery 2017;162:397-407.

58. Mangione-Smith R, Roth CP, Britto MT, et al. Development and Testing of the Pediatric Respiratory IIIness Measurement System (PRIMES) Quality Indicators. Hosp Pediatr 2017;7:125-33.

59. Odetola FO, Freed G, Shevrin C, et al. In-hospital qualityof-care measures for pediatric sepsis syndrome. Pediatrics 2017; 140:e20170350-8.

60. Parast L, Bardach NS, Burkhart Q, et al. Development of new quality measures for hospital-based care of suicidal youth. Acad Pediatr 2018;18:248-55.

61. Mackinnon NJ, Hepler CD. Preventable drug-related morbidity in older adults 1. Indicator development. J Manag Care Pharm 2002;8:365-71.

62. Robertson HA, MacKinnon NJ. Development of a list of consensusapproved clinical indicators of preventable drug-related morbidity in older adults. Clin Ther 2002;24:1595-613.

63. Burge FI, Bower K, Putnam W, et al. Quality indicators for cardiovascular primary care. Can J Cardiol 2007;23:383-8.

64. Kröger E, Tourigny A, Morin D, et al. Selecting process quality indicators for the integrated care of vulnerable older adults affected by cognitive impairment or dementia. BMC Health Serv Res 2007;7:195.

65. Dt K, Wijeysundera HC, Zhu X, et al. Canadian quality indicators for percutaneous coronary interventions. Can J Cardiol 2008:24:899-903.

66. MacKinnon NJ, Hartnell NR, Black EK, et al. Development of clinical indicators for type 2 diabetes. Canadian Pharmacists Journal 2008;141:120-8.

67. Nigam R, Mackinnon NJ, U D, et al. Development of canadian safety indicators for medication use. Healthc Q 2008;11:47-53. 
68. Jv T, Khalid L, Donovan LR, et al. Indicators of quality of care for patients with acute myocardial infarction. CMAJ: Canadian Medical Association Journal 2008;179:909-15.

69. Dixon E, Armstrong C, Maddern G, et al. Development of Quality Indicators of Care for Patients Undergoing Hepatic Resection for Metastatic Colorectal Cancer Using a Delphi Process. J Surg Res 2009;156:32-8.

70. Teresato GA, Lougheed MD, et al. Evidence-based performance indicators of primary care for asthma: a modified RAND Appropriateness Method. Int J Qual Health Care 2010;22:476-85.

71. Krzyzanowska MK, Barbera L, Elit L, et al. Identifying populationlevel indicators to measure the quality of cancer care for women. Int J Qual Health Care 2011;23:554-64.

72. Schull MJ, Guttmann A, Leaver CA, et al. Prioritizing performance measurement for emergency department care: consensus on evidencebased quality of care indicators. CJEM 2011;13:300-9.

73. Addington DE, Mckenzie E, Wang J, et al. Development of a core set of performance measures for evaluating schizophrenia treatment services. Psychiatr Serv 2012;63:584-91.

74. Stang AS, Straus SE, Crotts J, et al. Quality indicators for high acuity pediatric conditions. Pediatrics 2013;132:752-62.

75. Darling G, Malthaner R, Dickie J, et al. Quality indicators for nonsmall cell lung cancer operations with use of a modified Delphi consensus process. Ann Thorac Surg 2014;98:183-90.

76. Nguyen GC, Devlin SM, Afif W, et al. Defining quality indicators for best-practice management of inflammatory bowel disease in Canada. Can J Gastroenterol Hepatol 2014;28:275-85.

77. Santana MJ, Stelfox HT. Trauma Quality Indicator Consensus Panel. Development and evaluation of evidence-informed quality indicators for adult injury care. Ann Surg 2014;259:186-92.

78. Barber CE, Patel JN, Woodhouse L, et al. Development of key performance indicators to evaluate centralized intake for patients with osteoarthritis and rheumatoid arthritis. Arthritis Res Ther 2015; $17: 322$.

79. Fernandes O, Gorman SK, Slavik RS, et al. Development of clinical pharmacy key performance indicators for hospital pharmacists using a modified Delphi approach. Ann Pharmacother 2015;49:656-69.

80. Khare SR, Batist G, Bartlett G. Identification of performance indicators across a network of clinical cancer programs. Curr Oncol 2016;23:81-90.

81. McKelvie RS, Heckman GA, Blais C, et al. Canadian Cardiovascular Society Quality Indicators for Heart Failure. Can J Cardiol 2016;32:1038.e5-1038.e9.

82. Khare SR, Aprikian A, Black P, et al. Quality indicators in the management of bladder cancer: A modified Delphi study. Urol Oncol 2017:35:328-34

83. TuJV, Maclagan LC, KoDT, et al. The Cardiovascular Health in Ambulatory Care Research Team performance indicators for the primary prevention of cardiovascular disease: a modified Delphi panel study. CMAJ open 2017;5:E315-E321.

84. Tu K, Bevan L, Hunter K, et al. Quality indicators for the detection and management of chronic kidney disease in primary care in Canada derived from a modified Delphi panel approach. CMAJ Open 2017;5:E74-E81.

85. Chartrand M, Guénette L, Brouillette D, et al. Development of Quality Indicators to Assess Oral Anticoagulant Management in Community Pharmacies for Patients with Atrial Fibrillation. J Manag Care Spec Pharm 2018;24:357-65.

86. Mukerji G, Halperin I, Hunter K, et al. Developing a set of indicators to monitor quality in ambulatory diabetes care using a modified Delphi panel process. International Journal for Quality in Health Care 2018;30:65-74

87. Muijrers PEM, Janknegt R, Sijbrandij J, et al. Prescribing indicators: Development and validation of guideline-based prescribing indicators as an instrument to measure the variation in the prescribing behaviour of general practitioners. Eur J Clin Pharmacol 2004;60:739-46.

88. Mourad SM, Hermens RPMG, Nelen WLDM, et al. Guideline-based development of quality indicators for subfertility care. Hum Reprod 2007;22:2665-72

89. Drašković I, Vernooij-Dassen M, Verhey F, et al. Development of quality indicators for memory clinics. Int $J$ Geriatr Psychiatry 2008;23:119-28.

90. Martirosyan L, Braspenning J, Denig P, et al. Prescribing quality indicators of type 2 diabetes mellitus ambulatory care. Quality and Safety in Health Care 2008;17:318-23.

91. van der Ploeg E, Depla MFIA, Shekelle P, et al. Developing quality indicators for general practice care for vulnerable elders; transfer from US to The Netherlands. Quality and Safety in Health Care 2008;17:291-5.
92. Perry M, Drasković I, van Achterberg T, et al. Development and validation of quality indicators for dementia diagnosis and management in a primary care setting. J Am Geriatr Soc 2010;58:557-63.

93. Stienen JJC, Tabbers MM, Benninga MA, et al. Development of quality indicators based on a multidisciplinary, evidence-based guideline on pediatric constipation. Eur J Pediatr 2011;170:1513-9.

94. Wierenga PC, Klopotowska JE, Smorenburg SM, et al. Quality Indicators for In-Hospital Pharmaceutical Care of Dutch Elderly Patients. Drugs Aging 2011;28:295-304.

95. Luitjes SH, Wouters MG, Franx A, et al. Guideline-based development of quality indicators for hypertensive diseases in pregnancy. Hypertens Pregnancy 2013;32:20-31.

96. van den Bosch CMA, Hulscher MEJL, Natsch S, et al. Development of quality indicators for antimicrobial treatment in adults with sepsis. BMC Infect Dis 2014;14:345

97. van den Bosch CM, Geerlings SE, Natsch S, et al. Quality indicators to measure appropriate antibiotic use in hospitalized adults. Clin Infect Dis 2015;60:281-91.

98. Woiski MD, Scheepers HC, Liefers J, et al. Guideline-based development of quality indicators for prevention and management of postpartum hemorrhage. Acta Obstet Gynecol Scand 2015;94:1118-27.

99. Hommel I, van Gurp PJ, Tack CJ, et al. Perioperative diabetes care: development and validation of quality indicators throughout the entire hospital care pathway. BMJ Qual Saf 2016;25:525-34.

100. Smits KPJ, Sidorenkov G, Bilo HJG, et al. Development and initial validation of prescribing quality indicators for patients with chronic kidney disease. Nephrology Dialysis Transplantation 2016;31:1876-86.

101. Smits KP, Sidorenkov G, Kleefstra N, et al. Development and validation of prescribing quality indicators for patients with type 2 diabetes. Int J Clin Pract 2017;71:e12922.

102. Broccoli MC, Moresky R, Dixon J, et al. Defining quality indicators for emergency care delivery: findings of an expert consensus process by emergency care practitioners in Africa. BMJ Glob Health 2018;3:e000479.

103. Caughey GE, Kalisch Ellett LM, Wong TY. Development of evidencebased Australian medication-related indicators of potentially preventable hospitalisations: a modified RAND appropriateness method. BMJ Open 2014:4:e004625.

104. Nag N, Millar J, Davis ID, et al. Development of Indicators to Assess Quality of Care for Prostate Cancer. Eur Urol Focus 2018:4:57-63.

105. O'Connor DW, D'Cunha C, Clifton T, et al. Quality indicators of psychotropic prescribing to people with dementia in aged psychiatry inpatient units. Aging Ment Health 2017:1-6.

106. Sibthorpe B, Agostino J, Coates $\mathrm{H}$, et al. Indicators for continuous quality improvement for otitis media in primary health care for Aboriginal and Torres Strait Islander children. Aust J Prim Health 2017;23:1-9.

107. Stordeur S, Vrijens F, Devriese S, et al. Developing and measuring a set of process and outcome indicators for breast cancer. Breast 2012;21:253-60.

108. Grypdonck L, Aertgeerts B, Luyten F, et al. Development of quality indicators for an integrated approach of knee osteoarthritis. $J$ Rheumatol 2014;41:1155-62.

109. Stordeur S, Vlayen J, Vrijens F, et al. Quality indicators for oesophageal and gastric cancer: a population-based study in Belgium, 2004-2008. Eur J Cancer Care 2015;24:376-86.

110. De Schreye R, Houttekier D, Deliens L, et al. Developing indicators of appropriate and inappropriate end-of-life care in people with Alzheimer's disease, cancer or chronic obstructive pulmonary disease for population-level administrative databases: A RAND/UCLA appropriateness study. Palliat Med 2017:31:932-45.

111. Leemans K, Deliens L, Van den Block L, et al. Systematic quality monitoring for specialized palliative care services: development of a minimal set of quality indicators for palliative care study (QPAC). Am $J$ Hosp Palliat Care 2017;34:532-46.

112. de Carvalho AGR, de Moraes APP, Tanaka LMS, et al. Quality in intensive care units: proposal of an assessment instrument. BMC Res Notes 2017;10:222.

113. Bao H, Yang F, Wang X, et al. Developing a set of quality indicators for breast cancer care in China. Int $J$ Qual Health Care 2015;27:291-6.

114. Chen L, Huang LH, Xing MY, et al. Using the Delphi method to develop nursing-sensitive quality indicators for the NICU. J Clin Nurs 2017;26:502-13.

115. Wu Q, Huang LH, Xing MY, et al. Establishing nursing-sensitive quality indicators for the operating room: A cross-sectional Delph survey conducted in China. Aust Crit Care 2017;30:44-52. 
116. Li W, Zeng L, Li J, et al. Development of indicators for assessing rational drug use to treat community-acquired pneumonia in children in hospitals and clinics: A modified Delphi study. Medicine 2017:96:e9308.

117. Wang X, Su S, Li S, et al. Development of quality indicators for non-small cell lung cancer care: a first step toward assessing and improving quality of cancer care in China. BMC Cancer 2017; $17: 603$.

118. Ju QY, Huang LH, Zhao XH, et al. Development of evidence-based nursing-sensitive quality indicators for emergency nursing: a delphi study. J Clin Nurs 2018.

119. Tang $X$, Chen $X$, Pang $Y$, et al. The development of quality indicators for home care in China. Int J Qual Health Care 2018;30:208-18.

120. Saust LT, Bjerrum L, Arpi M, et al. Quality indicators for the diagnosis and antibiotic treatment of acute respiratory tract infections in general practice: a RAND Appropriateness Method. Scand J Prim Health Care 2017;35:192-200.

121. Boulkedid R, Sibony O, Goffinet F, et al. Quality indicators for continuous monitoring to improve maternal and infant health in maternity departments: a modified Delphi survey of an international multidisciplinary panel. PLoS One 2013;8:e60663.

122. Follmann M, Schadendorf D, Kochs C, et al. Quality assurance for care of melanoma patients based on guideline-derived quality indicators and certification. J Dtsch Dermatol Ges 2014;12:139-47.

123. Hussein RJ, Krohn R, Kaufmann-Kolle P, et al. Quality indicators for the use of systemic antibiotics in dentistry. Z Evid Fortbild Qual Gesundhwes 2017;122:1-8.

124. Wakai A, O'Sullivan R, Staunton P, et al. Development of key performance indicators for emergency departments in Ireland using an electronic modified-Delphi consensus approach. Eur J Emerg Med 2013;20:109-14.

125. Murphy A, Wakai A, Walsh C, et al. Development of key performance indicators for prehospital emergency care. Emerg Med J 2016;33:286-92.

126. Barry E, O'Brien K, Moriarty F, et al. PIPc study: development of indicators of potentially inappropriate prescribing in children (PIPc) in primary care using a modified Delphi technique. BMJ Open 2016;6:e012079.

127. Fukuma S, Shimizu S, Niihata K, et al. Development of quality indicators for care of chronic kidney disease in the primary care setting using electronic health data: a RAND-modified Delphi method. Clin Exp Nephrol 2017;21:247-56.

128. Masaki $\mathrm{H}$, Kawai N, Matsumoto $\mathrm{K}$, et al. Consensus development of quality indicators for end-of-life care for elders in Japan. Int $J$ Nurs Pract 2017;23 Suppl 1:e12562.

129. Ueda K, Ohtera S, Kaso M, et al. Development of quality indicators for low-risk labor care provided by midwives using a RANDmodified Delphi method. BMC Pregnancy Childbirth 2017;17:315.

130. Pérez-Cuevas R, Doubova SV, Suarez-Ortega M, et al. Evaluating quality of care for patients with type 2 diabetes using electronic health record information in Mexico. BMC Med Inform Decis Mak 2012;12:50.

131. Doubova SV, Pérez-Cuevas R, Ortiz-Panozo E, et al. Evaluation of the quality of antenatal care using electronic health record information in family medicine clinics of Mexico City. BMC Pregnancy Childbirth 2014;14:168.

132. Petek D, Campbell S, Serec M, et al. Quality indicators of cardiovascular disease prevention for primary care in Slovenia. Zdravniski Vestnik 2012;81:687-98.

133. Minaya-Muñoz F, Medina-Mirapeix F, Valera-Garrido F. Quality measures for the care of patients with lateral epicondylalgia. BMC Musculoskelet Disord 2013:14:310.

134. Calvet X, Panés J, Alfaro N, et al. Delphi consensus statement: quality indicators for inflammatory bowel disease comprehensive care units. J Crohns Colitis 2014;8:240-51.

135. Ruiz-Canela-Cáceres J, Aquino-Llinares N, Sánchez-Diaz JM, et al. Indicators for childhood asthma in Spain, using the Rand method. Allergol Immunopathol 2015;43:147-56.

136. Soria-Aledo V, Angel-Garcia D, Martinez-Nicolas I, et al. Development and pilot study of an essential set of indicators for general surgery services. Cir Esp 2016;94:502-10.

137. Bianchi V, Spitale A, Ortelli L, et al. Quality indicators of clinical cancer care (QC3) in colorectal cancer. BMJ Open 2013;3:e002818.

138. Chung KP, Lai MS, Cheng SH, et al. Organization-based performance measures of cancer care quality: core measure development for breast cancer in Taiwan. Eur J Cancer Care 2008;17:5-18.

139. Chung KP, Chang YJ, Lai MS, et al. Is quality of colorectal cancer care good enough? Core measures development and its application for comparing hospitals in Taiwan. BMC Health Serv Res 2010;10:27.
140. Cantrill JA, Sibbald B, Buetow S. Indicators of the appropriateness of long-term prescribing in general practice in the United Kingdom: consensus development, face and content validity, feasibility, and reliability. Qual Health Care 1998;7:130-5.

141. Morris CJ, Cantrill JA. Preventing drug-related morbidity-the development of quality indicators. J Clin Pharm Ther 2003;28:295-305.

142. Steel N, Melzer D, Shekelle PG, et al. Developing quality indicators for older adults: transfer from the USA to the UK is feasible. Qual Saf Health Care 2004:13:260-4.

143. Tully MP, Javed N, Cantrill JA. Development and face validity of explicit indicators of appropriateness of long term prescribing. Pharm World Sci 2005;27:407-13.

144. Gill PJ, O'Neill B, Rose P, et al. Primary care quality indicators for children: measuring quality in UK general practice. Br J Gen Pract 2014;64:e752-e757.

145. Spencer R, Bell B, Avery AJ, et al. Identification of an updated set of prescribing--safety indicators for GPs. Br J Gen Pract 2014;64:e181-e190.

146. Campbell SM, Ludt S, Van Lieshout J, et al. Quality indicators for the prevention and management of cardiovascular disease in primary care in nine European countries. Eur J Cardiovasc Prev Rehabil 2008;15:509-15.

147. Adriaenssens N, Coenen S, Tonkin-Crine S, et al. European Surveillance of Antimicrobial Consumption (ESAC): disease-specific quality indicators for outpatient antibiotic prescribing. BMJ Qual Saf 2011;20:764-72.

148. Petersson IF, Strömbeck B, Andersen L, et al. Development of healthcare quality indicators for rheumatoid arthritis in Europe: the eumusc.net project. Ann Rheum Dis 2014;73:906-8.

149. Hermann RC, Mattke S, Somekh D, et al. Quality indicators for international benchmarking of mental health care. Int J Qual Health Care 2006;18 Suppl 1:31-8.

150. Barber CE, Marshall DA, Alvarez N, et al. Development of Cardiovascular Quality Indicators for Rheumatoid Arthritis: Results from an International Expert Panel Using a Novel Online Process. $J$ Rheumatol 2015;42:1548-55.

151. Ntoburi S, Hutchings A, Sanderson C, et al. Development of paediatric quality of inpatient care indicators for low-income countries - A Delphi study. BMC Pediatr 2010;10:90.

152. Idänpään-Heikkilä UM, Lambie L, Mattke $S$, et al. Selecting indicators for the quality of cardiac care at the health system leve in Organization for Economic Co-operation and Development countries. Int J Qual Health Care 2006;18 Suppl 1:39-44.

153. Australian Commission on Safety and Quality in Health Care. Practice-level indicators of safety and quality for primary health care specification: Australian Commission on Safety and Quality in Health Care. 2012 https://www.safetyandquality.gov.au/wpcontent/uploads/2012/02/Practice-level-indicators-for-primaryhealth-care-specification-V1.0-October-2012.pdf (accessed 5 May 2017).

154. Australian Commission on Safety and Quality in Health Care and NSW Therapeutic Advisory Group Inc. National Quality use of medicines indicators for australian hospitals Sydney: ACSQHC. 2014 https://www.safetyandquality.gov.au/wp-content/uploads/ 2014/11/SAQ127_National_QUM_Indicators_V14-FINAL-D1439602.pdf (accessed 5 May 2017).

155. the Department of Health \& Human Services, State Government of Victoria, Australia. Quality indicators in PSRACS resource materials 2015. 2015 https://www2.health.vic.gov.au/about/publications/poli ciesandguidelines/quality-indicators-psracs-resource-materials2015 (accessed 9 April 2018).

156. The NICE menu of general practice and clinical commissioning group indicators: The National Institute for Health and Care Excellence. 2016 https://www.nice.org.uk/Media/Default/ Standards-and-indicators/indicator-menu-update-aug-16.pdf (accessed 5 May 2017).

157. AfHRa Q. National Quality Measures Clearinghouse: U.S. Department of Health \& Human Services $2017 \mathrm{https}: / /$ www. qualitymeasures.ahrq.gov/ (accessed 5 April 2018).

158. Rubin HR, Pronovost P, Diette GB. The advantages and disadvantages of process-based measures of health care quality. Int J Qual Health Care 2001:13:469-74.

159. lezzoni LI. The risks of risk adjustment. JAMA 1997;278:1600-7.

160. Nau DP. Measuring pharmacy quality. J Am Pharm Assoc 2009;49:154-63.

161. Gardner K, Mazza D. Quality in general practice - definitions and frameworks. Aust Fam Physician 2012;41:151-4.

162. Silva C, Ramalho C, Luz I, et al. Drug-related problems in institutionalized, polymedicated elderly patients: opportunities for pharmacist intervention. Int J Clin Pharm 2015;37:327-34. 
163. Elliot-Smith A, Morgan MA, Elliot S. How do we compare? Applying UK pay for performance indicators to an Australian general practice. Aust Fam Physician 2010;39:43

164. Hannon KL, Lester HE, Campbell SM. Patients' views of pay for performance in primary care: a qualitative study. Br J Gen Pract 2012;62:322-8.

165. Wollersheim H, Hermens R, Hulscher M, et al. Clinical indicators: development and applications. Neth J Med 2007;65:15-22.

166. Mainz J. Developing evidence-based clinical indicators: a state of the art methods primer. Int J Qual Health Care 2003;15 Supp $1: 5 i-11$
167. Kneeland PP, Fang MC. Current issues in patient adherence and persistence: focus on anticoagulants for the treatment and prevention of thromboembolism. Patient Prefer Adherence 2010;4:51-60.

168. Freedman JD, Gottlieb AB, Lizzul PF. Physician performance measurement: tiered networks and dermatology (an opportunity and a challenge). J Am Acad Dermatol 2011;64:1164-9.

169. Prakash B, Nadig P, Nayak A. Rational prescription for a dermatologist. Indian J Dermatol 2016;61:32-8.

170. Nadzam DM. Development of medication-use indicators by the Joint Commission on Accreditation of Healthcare Organizations. Am J Hosp Pharm 1991;48:1925-30. 